\title{
$T A^{\prime}$

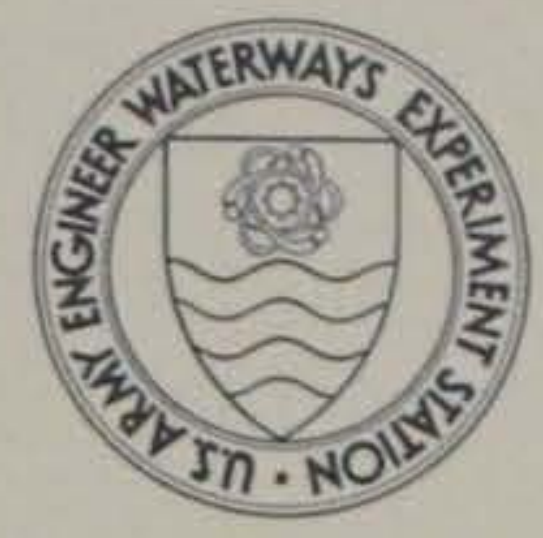 \\ USE OF SHEAR WAVES IN SEISMIC REFRACTION SURVEYING
}

by

Arley G. Franklin

Geotechnical Laboratory

U. S. Army Engineer Waterways Experiment Station

P. O. Box 631, Vicksburg, Miss. 39180

August 1979

Final Report

Approved For Public Release; Distribution Unlimited

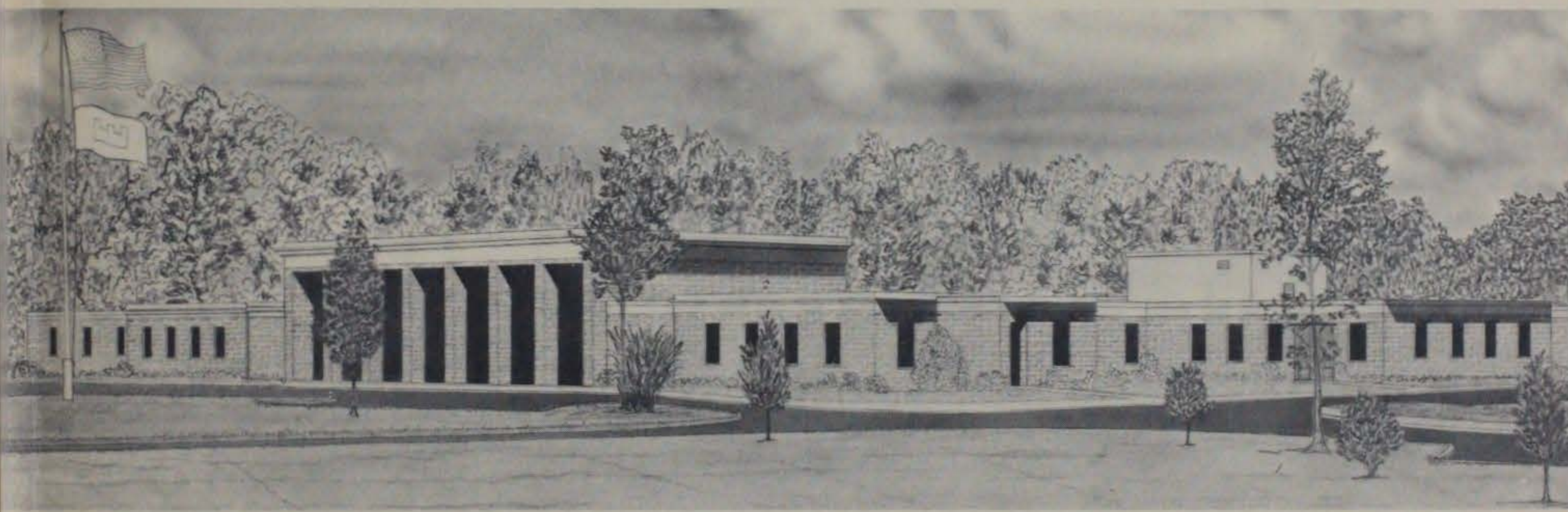

Prepared for Assistant Secretary of the Army (RED)

Washington, D. C. 20310

Under Project No. 4AI6II0IA9ID

UBRAFY BRAFCH

TECHINICAL WFORMATIOA CENTER

US ARMY ENGINEER WATERWAYS EXPERIMENT STATIONN 
Unclassified

SECURITY CLASSIFICATION OF THIS PAGE (Whon Data Entered)

\begin{tabular}{|c|c|}
\hline REPORT DOCUMENTATION PAGE & $\begin{array}{c}\text { READ INSTRUCTIONS } \\
\text { BEFORE COMPLETING FORM }\end{array}$ \\
\hline $\begin{array}{l}\text { 1. REPORT NUMBER } \\
\begin{array}{l|l|}\text { MISCELLANEOUS PAPER GL-79-17 } & \text { 2. GOVT ACCESSION NO. } \\
\end{array}\end{array}$ & 3. RECIPIENT'S CATALOG NUMBER \\
\hline \multirow[t]{2}{*}{$\begin{array}{l}\text { 4. TITLE (and Subtitie) } \\
\text { USE OF SHEAR WAVES IN SEISMIC REFRACTION SURVEYING }\end{array}$} & $\begin{array}{l}\text { 5. TYPE OF REPORT \& PERIOD COVERED } \\
\text { Final report }\end{array}$ \\
\hline & 6. PERFORMING ORG. REPORT NUMBER \\
\hline $\begin{array}{l}\text { 7. AUTHOR(0) } \\
\text { Arley G。 Franklin }\end{array}$ & 8. CONTRACT OR GRANT NUMBER(s) \\
\hline $\begin{array}{l}\text { 9. PERFORMING ORGANIZATION NAME AND ADDRESS } \\
\text { U. S. Army Engineer WaterwayS Experiment Station } \\
\text { Geotechnical Laboratory } \\
\text { P. 0. Box 631, Vicksburg, Miss. } 39180\end{array}$ & $\begin{array}{l}\text { 10. PROGRAM ELEMENT, PROJECT, TASK } \\
\text { AREA \& WORK UNIT NUMBERS } \\
\text { Project No. 4AI61101A91D }\end{array}$ \\
\hline \multirow{2}{*}{$\begin{array}{l}\text { 11. CONTROLLING OFFICE NAME AND ADDRESS } \\
\text { Assistant Secretary of the Army (R\&D) } \\
\text { Washington, D。 C. } 20310\end{array}$} & $\begin{array}{l}\text { 12. REPORT DATE } \\
\text { August } 1979\end{array}$ \\
\hline & $\begin{array}{l}\text { 13. NUMBER OF PAGES } \\
42\end{array}$ \\
\hline \multirow{2}{*}{ 14. MONITORING AGENCY NAME A ADDRESS(If difierent from Controlling Office) } & $\begin{array}{l}\text { 15. SECURITY CLASS. (of this roport) } \\
\text { Unclassified }\end{array}$ \\
\hline & $\begin{array}{l}\text { 15a. DECLASSIFICATION/DOWNGRADING } \\
\text { SCHEDULE }\end{array}$ \\
\hline
\end{tabular}

16. DISTRIBUTION STATEMENT (of this Report)

Approved for public release; distribution unlimited.

17. DISTRIBUTION STATEMENT (of the abstract ontered in Block 20, If different frock Report)

18. SUPPLEMENTARY NOTES

19. KEY WORDS (Continuo on reverse side if necessary and identify by block number)

Compression waves

Shear waves

Refraction

Subsurface exploration

Seismic refraction

Wave refraction

Seismic surveys

Wave velocity

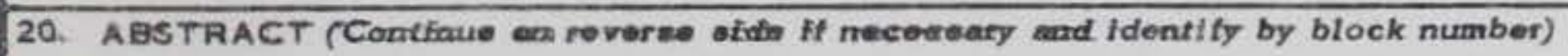

The nearly universal practice in surface seismic refraction surveying for engineering purposes is to use only data obtained from compression waves, or P-waves, which are always the first arrivals and are thus the most easily detected and identified. Most seismic refraction surveys used in geotechnical practice are concerned with identifying depths to various layer boundaries or to the bedrock surface. P-wave velocities are normally obtained in the course of

(Continued) 


\section{ABSTRACT (Continued)}

such surveys, but are usually of only secondary interest in seismic analyses. Shear wave, or S-wave, velocities, on the other hand, are of primary interest in engineering practice when they are needed for use as input to seismic analyses of structures. The S-wave velocity of the surface layer is frequently measured with a field survey using a layout similar to that of a refraction survey. However, refracted S-wave signals are not normally used. In principle, S-wave returns obtained by refraction through subsurface strata should be useful for measuring the S-wave velocities of these strata. In practice, however, results are often disappointing.

In this report, the current state of the art in generating and discriminating refracted S-waves at the ground surface is described, and some theoretical and practical considerations in the propagation and discrimination of refracted S-waves are discussed. Theoretical considerations and experience indicate that horizontally polarized shear waves, or $\mathrm{S}_{\mathrm{h}}$-waves, are the best type of signal to use in S-wave refraction surveys. The $\mathrm{S}_{\mathrm{h}}$-wave is easier to distinguish from the $\mathrm{P}$-wave than is the vertically polarized shear wave, or $\mathrm{S}_{\mathrm{V}}$-wave. Also, there is less energy lost through conversion to P-waves at interfaces between layers. Surface traction applied through hammer blows against a plank has proved to be a good source of $\mathrm{S}_{\mathrm{h}}$-wave energy.

Phase reversal in the $S_{h}$-wave with reversal of the impulse direction in the source may be useful in discriminating $\mathrm{S}_{\mathrm{h}}$-waves. By superimposing and comparing signals obtained with reversed directions of impulse, or with a signal enhancement seismograph and alternating reversal of both source motion and geophone polarity, the $S_{h}$-wave can be enhanced while both the $\mathrm{P}$-wave and the noise components are suppressed. Examples are shown of field data obtained by both of these methods.

The studies described show that it is feasible to use refracted S-waves for the investigation of subsurface strata, at least to limited depths and under favorable conditions. The most serious limitation in the present state of the art appears to be that currently available S-wave sources are severely limited in the strength of the S-wave signal that they can apply. This limitation imposes limits on the length of the line over which a signal can be detected and therefore on the effective depth of investigation. 


\section{PREFACE}

The study described in this report was performed during the period December 1976-September 1978 under Project No. 4Al61101A91D and was sponsored by the Assistant Secretary of the Army (R\&D) under the InHouse Laboratory Independent Research (ILIR) Program.

The report was prepared by Dr. Arley G. Franklin of the Earthquake Engineering and Geophysics Division (EE\&GD), Geotechnical Laboratory (GL), U. S. Army Engineer Waterways Experiment Station (WES), Vicksburg, Miss. Field work at Austin, Texas, and Redwood, Miss., was performed by Messrs. Glenn B. Landers and Edwin S. Stewart, Jr. The field work at Alben Barkley Dam was done by Messrs. Landers and Donald H. Douglas as part of the work for the dynamic analysis of the dam and was sponsored by the U. S. Army Engineer District, Nashville. The drawing for Figure 12 of the report was provided by Mr. Stafford S. Cooper.

The work was done under the general direction of Drs. Francis G. McLean and Paul F. Hadala, former Chief and Chief, respectively, EE\&GD, and Mr. James P. Sale, Chief, GL.

Director of WES during the performance of this work was COL John L. Cannon, CE. Technical Director was Mr. F. R. Brown. 
PREFACE . . . . . . . . . . . . . . . . . . . . . . . . .

CONVERSION FACTORS, U. S. CUSTOMARY TO METRIC (SI)

UNITS OF MEASUREMENT

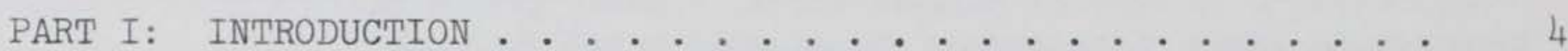

Background . . . . . . . . . . . . . . . . . . 4

Purpose and Scope ... . . . . . . . . . . . . . 5

PART II: PROPAGATION OF SHEAR WAVES IN A LAYERED EARTH . . . . . 6

PART III: SHEAR WAVE SOURCES . . . . . . . . . . . . . . 18

PART IV: DETECTION AND DISCRIMINATION OF $\mathrm{S}_{h}$-WAVES . . . . . . 24

Time of Arrival . . . . . . . . . . . . . . . 24

Direction of Particle Motion . . . . . . . . . . . . 24

Phase Relations . . . . . . . . . . . . . . . 25

PART V: FIELD STUDIES . . . . . . . . . . . . . . 30

PART VI: CONCLUSIONS ................. . . . . 40

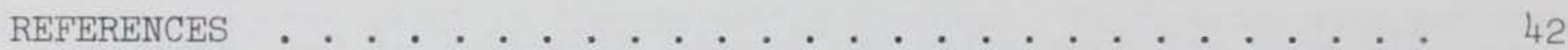


CONVERSION FACTORS, U. S. CUSTOMARY TO METRIC (SI)

UNITS OF MEASUREMENT

U. S. customary units of measurement used in this report can be converted to metric (SI) units as follows:

$\frac{\text { Multiply }}{\text { feet }}$
feet per second
inches
pounds (mass)

$\frac{\text { By }}{0.3048}$
0.3048
2.54
0.45359237

To Obtain
metres
metres per second
centimetres
kilograms




\section{USE OF SHEAR WAVES IN SEISMIC REFRACTION SURVEYING}

\section{PART I: INTRODUCTION}

\section{Background}

1. In United States practice, seismic refraction surveys are used very extensively in engineering exploration for the purpose of detecting and defining subsurface geologic boundaries, defining soil and rock layers, determining thickness of overburden, and the like. The nearly universal practice is to use only data obtained from compression waves, or $\mathrm{P}$-waves, which are always the first waves arriving at a geophone and are thus the most easily detected and identified.

2. In the course of a seismic refraction survey, compression wave velocities of surface and subsurface strata are normally obtained but are usually considered a by-product of the investigation, since the compression wave velocities themselves are usually of only secondary interest. Shear wave velocities, on the other hand, are of primary interest when they are needed as input to seismic analyses of structures such as buildings or embankments. If the density of the soil material is known, the shear wave velocity yields directly the value of shear modulus applicable at low strain levels and, in many analyses, can be used interchangeably with it. The shear wave velocity of the surface layer is frequently measured with a field survey using a layout similar to that of a conventional refraction survey. However, refracted shear wave signals are not normally used for investigations of subsurface strata.

3. In principle, shear wave returns obtained by refraction through subsurface strata should be useful for measuring the shear wave velocities of the subsurface strata. In practice, however, it is difficult to transmit and receive shear wave signals over long lines, and refracted shear wave arrivals are often difficult to identify on seismic records. According to Mooney (1974): "In practice, results have been 
uniformly disappointing." Shear wave velocities of subsurface materials are usually measured by means of downhole or crosshole surveys, both of which require borings for access to the subsurface strata.

4. Routine use of shear waves in refraction surveys will require improvements over present methods of generating, detecting, and discriminating shear waves, since limitations affecting the present state of, the art lie in all three areas. Such developments can produce economic savings as well as better quality in subsurface exploration by reducing the number of borings needed and by increasing the amount of information that çan be obtained in areas between borings.

\section{Purpose and Scope}

5. The purposes of this report are to evaluate, by means of field tests and review of relevant theoretical and operational aspects of the problem, the feasibility of using refracted shear waves for the investigation of subsurface strata and to suggest promising approaches to the development of improved methods of generating, detecting, and discriminating refracted shear waves.

6. In this report, the current state of the art is briefly described, and some theoretical and practical considerations in the propagation and discrimination of shear waves are discussed. Examples are shown of field data obtained by two methods that make use of the reversibility of phase in horizontally polarized shear waves with reversal of the excitation applied to the source. 


\section{PART II: PROPAGATION OF SHEAR WAVES IN A LAYERED EARTH}

7. If a dynamic disturbance occurs in the interior of a linearly elastic, isotropic, infinite medium, the disturbance spreads so that every particle of the medium is eventually affected. By Huygen's principle, each particle of the medium, once it is excited, acts as a new source of disturbance and radiates energy in all directions. Consequently, there are an infinite number of paths over which the disturbance may travel from a source to any other point in the medium (Figure 1). The path of greatest interest is the path that requires the shortest time to traverse; such a path is called a ray path.

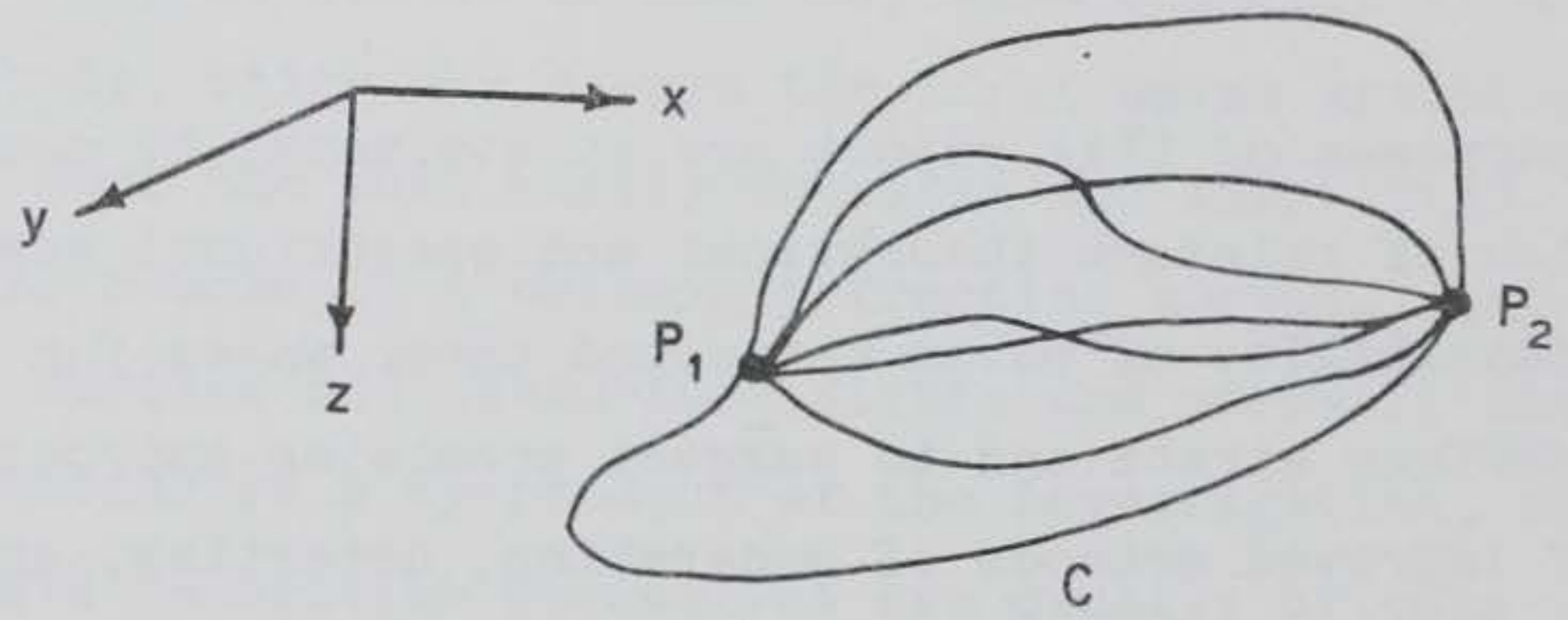

Figure 1. Paths of wave propagation in an elastic medium

8. The condition of minimum travel time is defined by the relation

$$
t=\int_{P_{1}}^{P_{2}} \frac{d s}{v(s)}=a \text { minimum }
$$

where $s$ is the distance from $P_{1}$ along the propagation path, $v(s)$ is the velocity of wave propagation as a function of location in the medium, and the integral is a line integral evaluated along the path C from $\mathrm{P}_{1}$ to $\mathrm{P}_{2}$.

9. If the velocity of wave propagation $v$ is constant throughout the medium, then Equation 1 can be written as 


$$
t=\frac{1}{v} \int_{P_{1}}^{P_{2}} d s
$$

in which case the integral is merely the length of the curve. The path of shortest time is therefore obviously a minimum when $C$ is a straight line. On the other hand, if the velocity of wave propagation $\mathrm{v}(\mathrm{s})$ is not a constant, the path of minimum travel time may be a curve of some type.

10. If the ray path crosses a boundary between two media with different velocities of wave propagation $v_{1}$ and $v_{2}$, it may change direction at the boundary, though it must follow a straight line within each medium. This situation is shown in Figure 2. The geometry of the system is defined by $D$, the component of the distance between $P_{1}$ and $\mathrm{P}_{2}$ in the direction of the boundary, and the perpendicular distances $d_{1}$ and $d_{2}$ from $P_{1}$ and $P_{2}$, respectively, to the

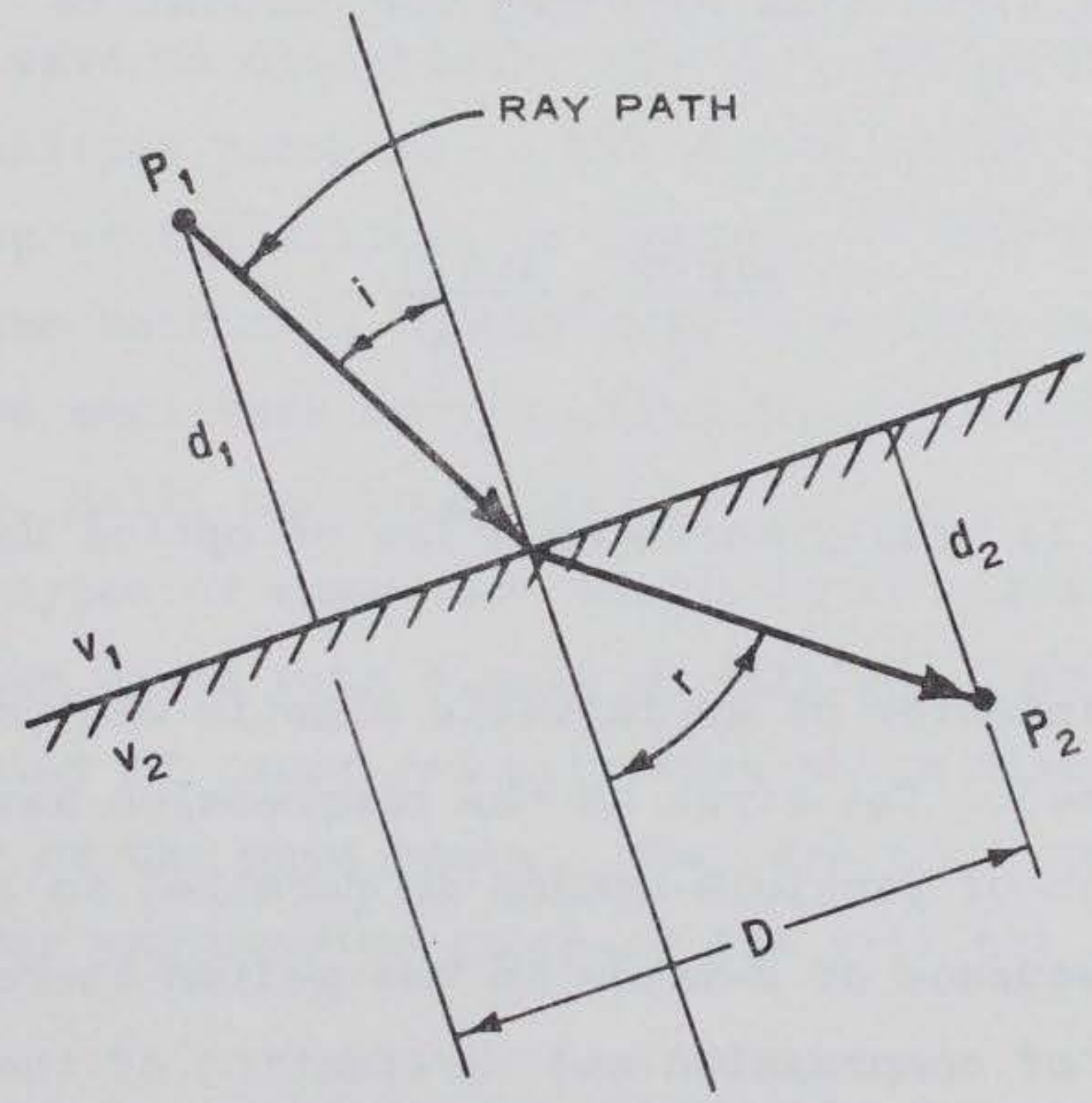

Figure 2. Refraction of ray path at boundary between media with different velocities of wave propagation 
boundary. The ray path meets the boundary at some angle of incidence $i$ and leaves the boundary at an angle of refraction $r$. The travel time from $P_{1}$ to $P_{2}$ is given by

$$
t=\frac{d_{1}}{v_{1} \cos i}+\frac{d_{2}}{v_{2} \cos r}
$$

Differentiating Equation 3 with respect to the angle of incidence i and using the condition

$$
d_{1} \tan i+d_{2} \tan r=D
$$

yields

$$
\frac{d t}{d i}=\frac{\sin i}{v_{1}}-\frac{\sin r}{v_{2}}
$$

The condition of minimum time requires the derivative $\frac{d t}{d i}$ to vanish; thus,

$$
\frac{\sin i}{v_{1}}=\frac{\sin r}{v_{2}}
$$

This relationship is widely known as a law of optics under the name Snell's law.

11. In the interior of an infinite elastic medium, two types of waves are propagated. The first is the compression wave, or $\mathrm{P}$-wave, in which the direction of particle motion is parallel to the path of wave propagation. A sequence of $\mathrm{P}$-waves in the medium therefore consists of alternating zones of compression and rarefaction of the material. The velocity of propagation of the $\mathrm{P}$-wave $\mathrm{v}_{\mathrm{P}}$ is given by:

$$
v_{P}=\sqrt{\frac{E(1-v)}{\rho(1+v)(1-2 v)}}
$$


where $\mathrm{E}$ is Young's modulus, $v$ is Poisson's ratio, and $\rho$ is the mass density of the medium.

12. The shear wave, or S-wave, involves only shear deformations, not volume change. The particle motions are therefore transverse (perpendicular) to the direction of propagation of the shear wave. The shear wave velocity, $\mathrm{v}_{\mathrm{S}}$, is given by

$$
v_{S}=\sqrt{\frac{G}{\rho}}
$$

where $G$ is the shear modulus of the material.

13. The velocity of the $\mathrm{P}$-wave is always greater than that of the S-wave, and the velocity difference leads to a separation of the compression and shear waves in time.

14. In a layered earth, there are other types of waves generated at free surfaces, such as the ground surface, and at interfaces between layers of materials with different properties. The most important of these is the Rayleigh wave, or R-wave, which normally forms a significant part of the wave train at the ground surface. The particle motion in the Rayleigh wave is elliptical; that is, the path followed by a particle is an ellipse parallel to the direction of wave advance. The motion at the top of the ellipse is opposite to the direction of wave advance and at the bottom is in the same direction as the wave advance. The Rayleigh wave amplitude decays exponentially with distance from the surface (Richart, Hall, and Woods 1970).

15. Other types of waves are generated by the interaction of compression and shear waves with single or multiple interfaces. These waves are generally of lower velocity than those described above and form later parts of the wave train. They are not important in seismic investigations for engineering purposes and will not be further considered here.

16. In examining the behavior of the shear wave, further attention must be given to the direction of the particle motion within the plane perpendicular to the direction of the wave advance. It will be assumed that interfaces between layers in the medium are horizontal. The 
particle displacement in the shear wave can then be resolved into horizontal and vertical components that are respectively parallel and perpendicular to the interfaces, and the two components can be examined separately. The first component (see Figure 3) is called the horizontally polarized shear wave, or $\mathrm{S}_{\mathrm{h}}$-wave, and the second is called the vertically polarized shear wave, or $\mathrm{S}_{\mathrm{V}}$-wave. In principle, and sometimes in practice, the velocity of the medium may be anisotropic, a consequence of which would be that the $\mathrm{S}_{\mathrm{V}}$ - and $\mathrm{S}_{\mathrm{h}}$-waves would be propagated at different velocities and thus would arrive at a detector at different times. However, for the purposes of the present discussion, it will be assumed that the medium is isotropic with respect to both $\mathrm{P}$ - and $\mathrm{S}$-wave velocities.

17. Figure 4 shows an example of the typical wave train that might be detected by a vertically oriented geophone on the ground surface at some distance from the source of a seismic disturbance. The time indicated as "zero time" represents the initiation of the disturbance. It is detected by a transducer located at the source and

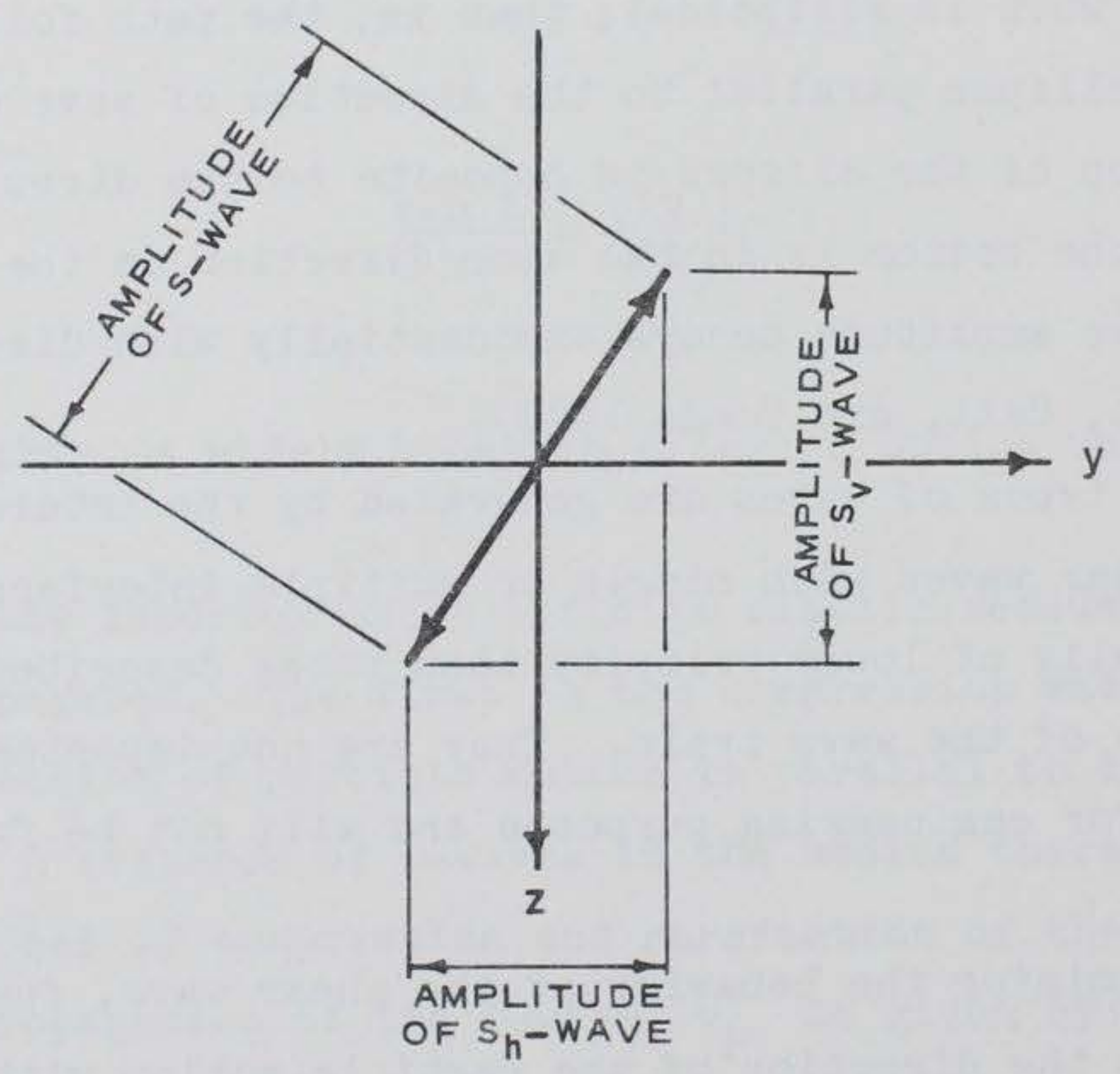

Figure 3. Resolution of S-wave into $\mathrm{S}_{\mathrm{V}}$ - and $\mathrm{S}_{\mathrm{h}}$-wave components 


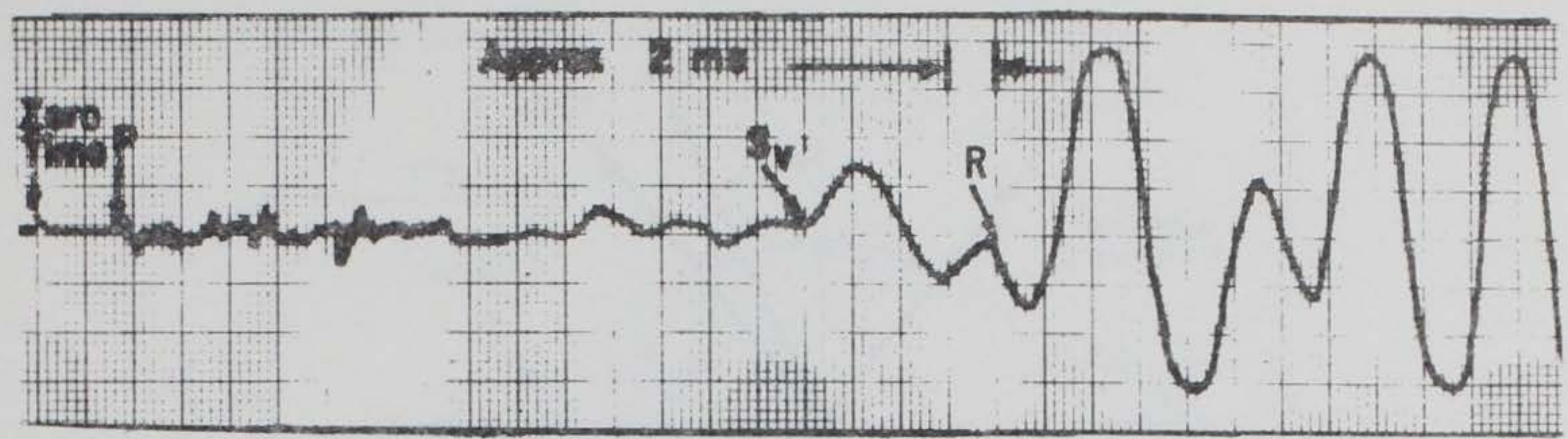

TIME

Figure 4. Features of wave train as detected by a vertically oriented geophone at some distance from the source

displayed on the same record. The time marked "p" represents the arrival of the $\mathrm{P}$-wave and is the first direct indication of the disturbance at the geophone. The time marked "S " represents the arrival of the vertically polarized shear wave, and the time marked " $R$ " represents the arrival of the Rayleigh wave. Typically, the velocity of propagation of the R-wave is within about 10 percent of the S-wave velocity.

18. The relative amounts of energy contained in $\mathrm{P}-$ and $\mathrm{S}$-waves depend on the nature of the source. Generally speaking, a highly symmetrical disturbance, such as an explosion in the interior of the medium, produces the greatest amount of energy in the P-wave, while a highly unbalanced or antisymmetrical source gives the greatest concentration of energy in the S-wave. Attenuation of the seismic energy occurs through geometric damping, which is the diffusion of the energy into ever-increasing volumes of the medium by radiation, and through material damping, by which the energy of the seismic motions is converted to heat. In a layered medium, the energy contained in a particular wave type is further reduced where the wave impinges on an interface. This partitions some of the energy into waves of other types that result from the interaction of the incident wave with the interface. In the case of a $P$-wave $\left(P_{1}\right)$ incident at an interface between layers 1 and 2, as shown in Figure 5, four new waves are generated by the interaction: a reflected $\mathrm{P}$-wave $\mathrm{P}_{1} \mathrm{P}_{1}$, a transmitted $\mathrm{P}$-wave $\mathrm{P}_{1} \mathrm{P}_{2}$, a reflected S-wave $\mathrm{P}_{1} \mathrm{~S}_{1}$, and a transmitted $\mathrm{S}$-wave $\mathrm{P}_{1} \mathrm{~S}_{2}$. 


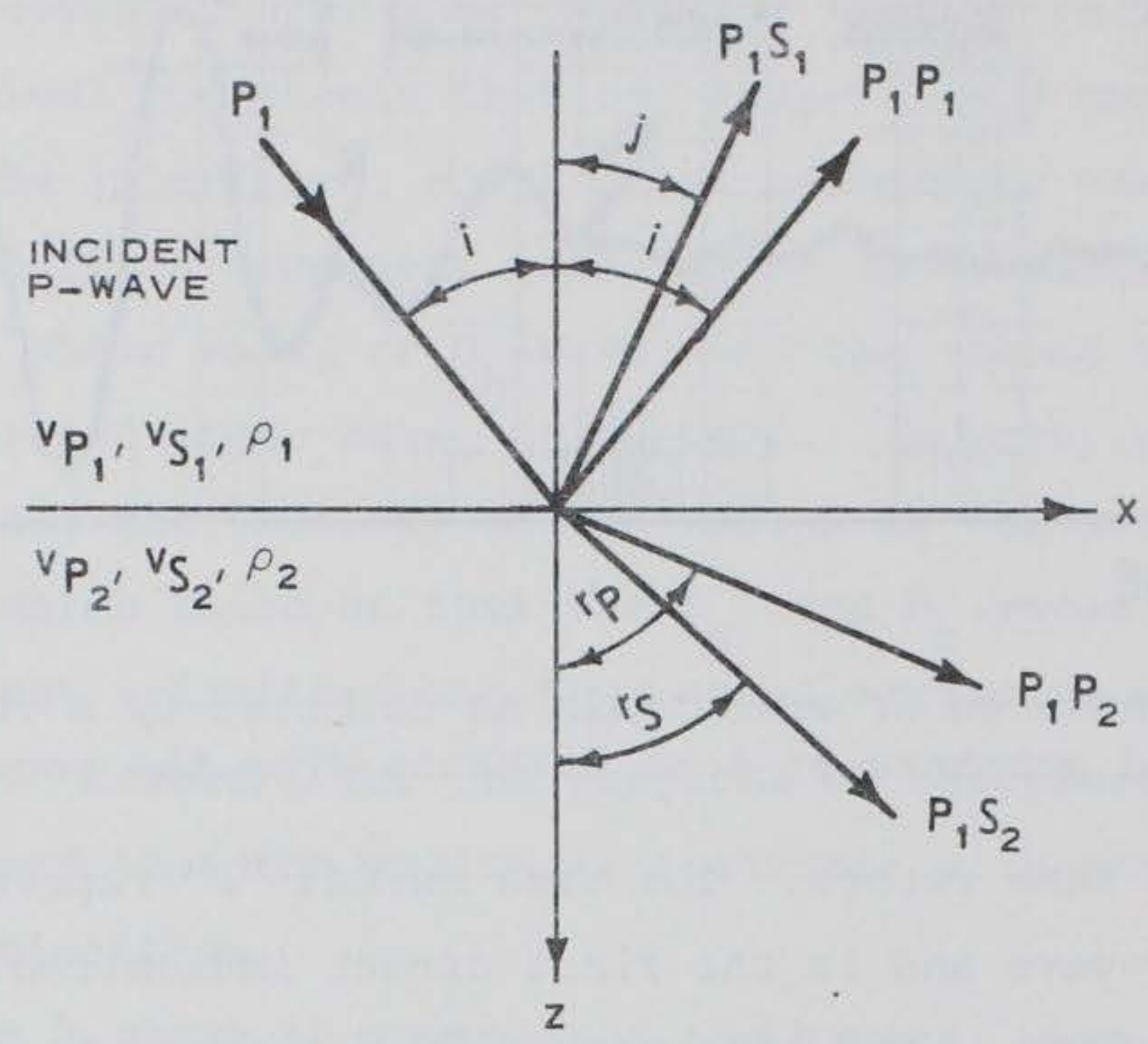

Figure 5. $\mathrm{P}$ - and $\mathrm{S}$-waves generated at interface by incident $\mathrm{P}$-wave

19. The relationship between the angle of incidence $i$ and the angles of reflection or refraction $j, r_{P}$, and $r_{S}$ of any of the other waves is given by Snell's law (Equation 6). This relationship holds for incident waves of either type and for both reflected and refracted waves of either type.

20. The phenomenon of critical refraction occurs when the angle of incidence is such that the angle of refraction $r$ equals 90 degrees. Since this condition means that $\sin r=1$, it can be seen from Equation 6 that the critical angle of incidence is given by arc sin $\left(v_{1} / v_{2}\right)$. For angles of incidence larger than the critical angle, near total reflection occurs, and very little energy is transmitted by refraction into the second medium. In general, the angle of critical incidence is different for each combination of incident and refracted wave types.

21. Systems of equations that can be solved to obtain the relative amplitudes and energies of various incident, refracted, and reflected wave types are given by Ewing, Jardetsky, and Press (1957). Figure 6 shows the energy distribution in reflected and refracted waves, as a percent of the energy content of the incident P-wave, for a particular 


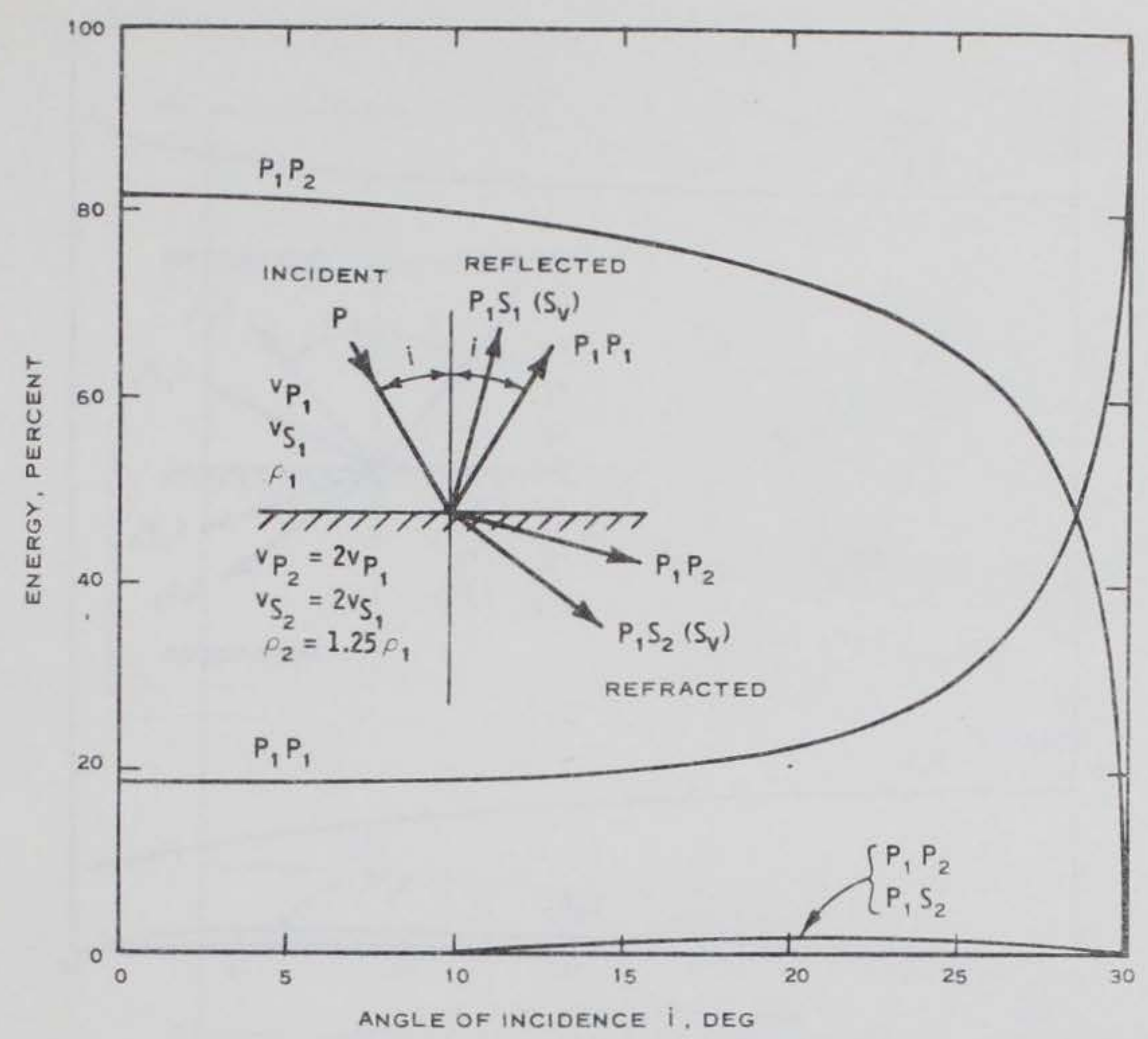

Figure 6. Energy distribution in reflected and refracted waves from an incident P-wave

set of velocity and density relationships (shown in the figure). It can be seen from the figure that the angle of critical incidence in this instance is 30 degrees. At small angles of incidence, most of the energy is contained in the refracted, or transmitted, P-wave and nearly all of the remainder in the reflected $\mathrm{P}$-wave. Only very minor amounts of energy, on the order of 1 percent, are contained in reflected and refracted $\mathrm{S}_{\mathrm{V}}$-waves. In theory, the incident $\mathrm{P}$-wave does not produce an $\mathrm{S}_{\mathrm{h}}$-wave at the interface. For angles of incidence greater than the critical angle, essentially 100 percent of the energy is contained in the reflected P-wave.

22. Figure 7 shows the distribution of energy resulting from an incident $\mathrm{S}_{\mathrm{V}}$-wave for the same interface conditions. At low angles of incidence, most of the energy is concentrated in the transmitted $\mathrm{S}_{\mathrm{V}}{ }^{-}$ wave, while nearly all of the remainder is in the reflected wave of the same type. While the figure does not indicate clearly what happens at 


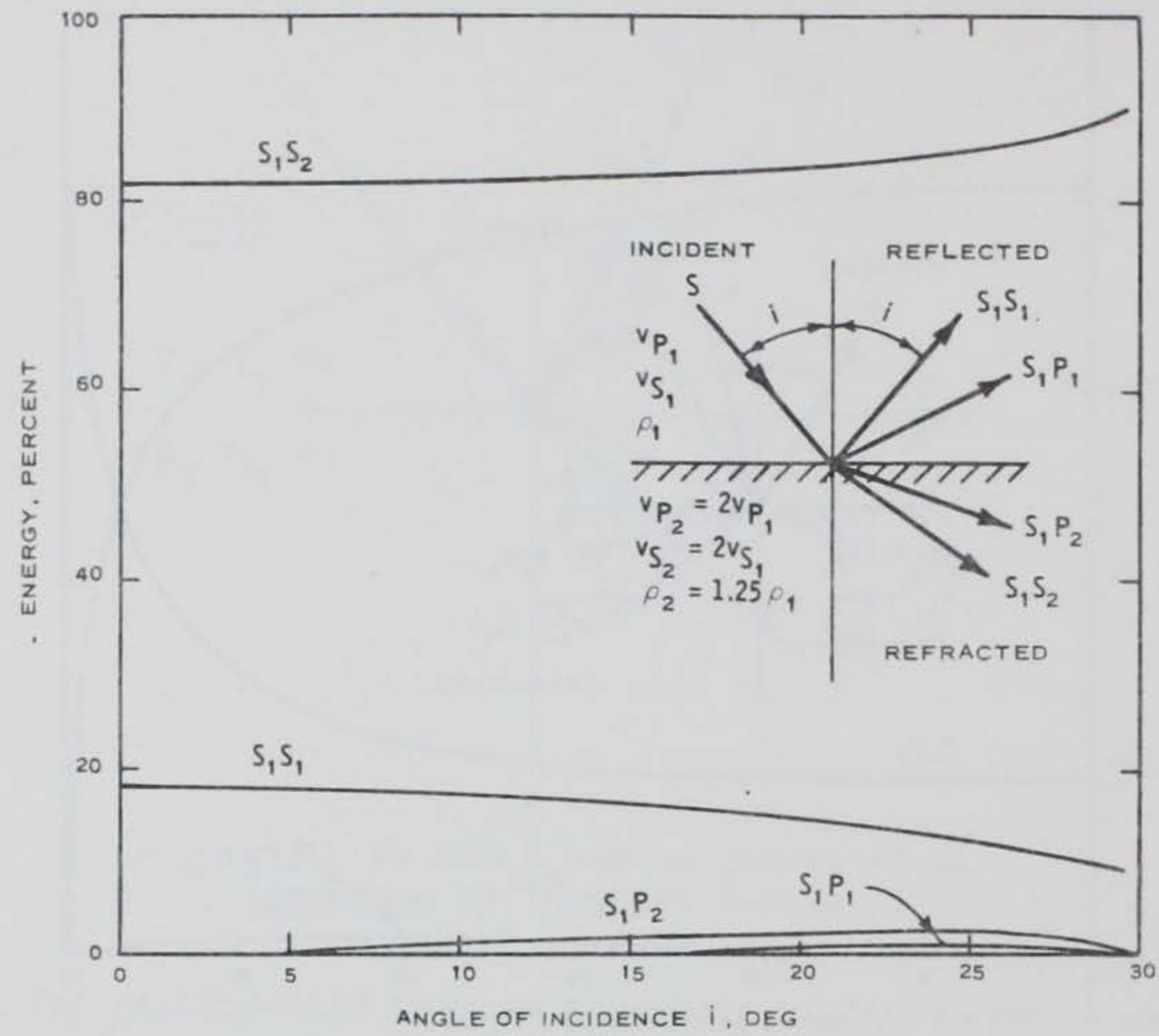

Figure 7. Energy distribution in reflected and refracted waves from an incident $\mathrm{S}_{\mathrm{V}}$-wave

the critical angle, the phenomenon of total reflection also occurs for the $\mathrm{S}_{\mathrm{V}}$-wave at angles of incidence above the critical. The case of an incident $\mathrm{S}_{h}$-wave is shown in Figure 8. For this type of wave, the particle motion is parallel to the interface, and no reflected or refracted waves of the $\mathrm{P}$ - or $\mathrm{S}_{\mathrm{V}}$-type occur. The phenomenon of total reflection is again evident in this figure, at an angle of 30 degrees.

23. The ray paths of primary interest in a seismic refraction survey over a two-layer system are shown in Figure 9 . The path $\mathrm{P}_{1} \mathrm{P}_{2} \mathrm{P}_{1}$ (which means that the first segment of the travel path is in the form of a $\mathrm{P}$-wave in medium 1 , the second a $\mathrm{P}$-wave in medium 2 , and the third a $\mathrm{P}$-wave again in medium 1) represents the path of the first refracted wave to arrive at the receiver. Also shown are the $\mathrm{S}_{1} \mathrm{~S}_{2} \mathrm{~S}_{1}$, which we would like to be able to identify and use, and the $\mathrm{S}_{1} \mathrm{P}_{2} \mathrm{P}_{1}, \mathrm{P}_{1} \mathrm{P}_{2} \mathrm{~S}_{1}$, and $\mathrm{S}_{1} \mathrm{P}_{2} \mathrm{~S}_{1}$ paths. These last three carry no information about the shear wave velocity of the second medium and only make the interpretation problem more difficult because they arrive ahead of the $\mathrm{S}_{1} \mathrm{~S}_{2} \mathrm{~S}_{1}$ 


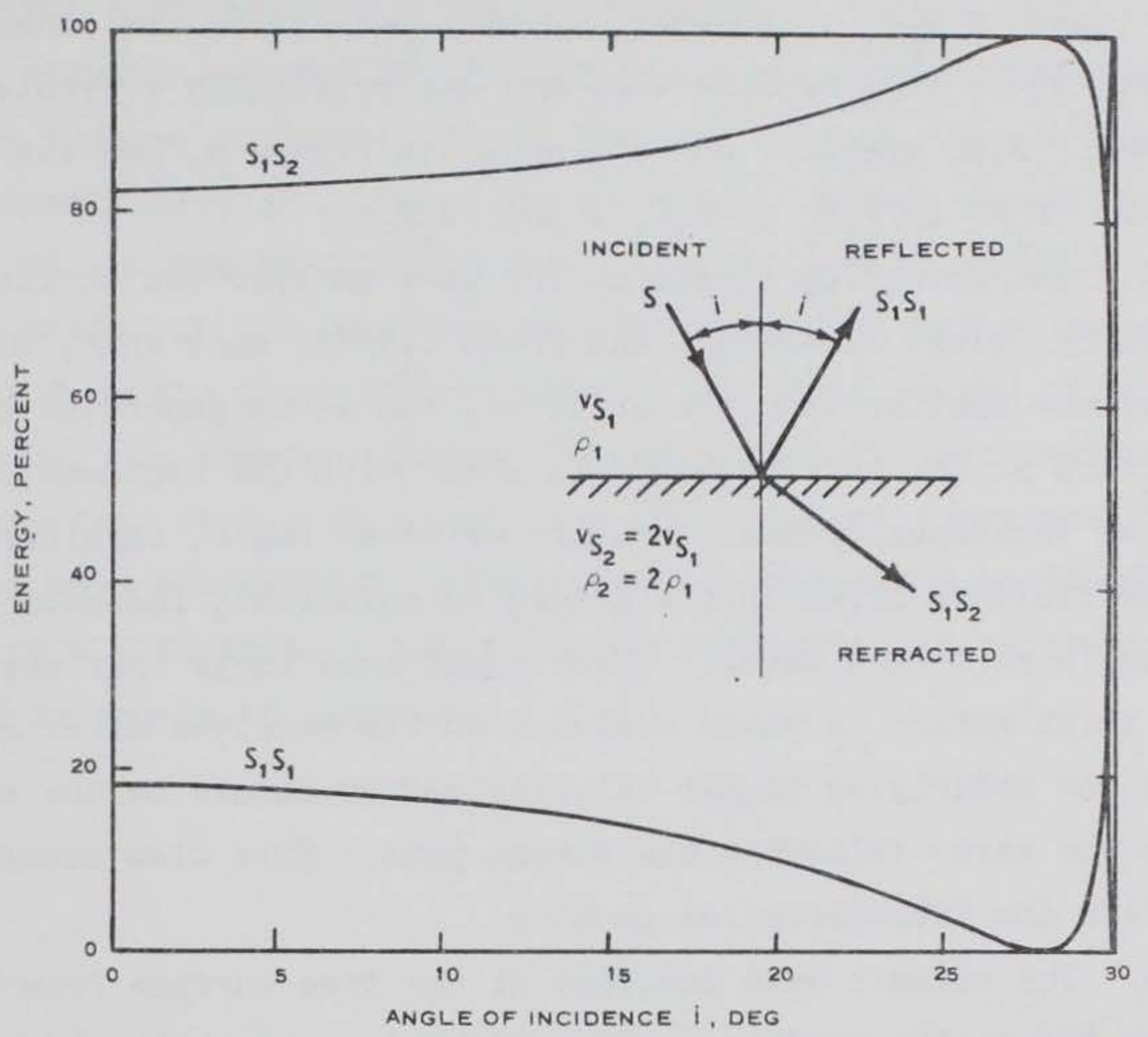

Figure 8. Energy distribution in reflected and refracted waves from an incident $\mathrm{S}_{h}$-wave

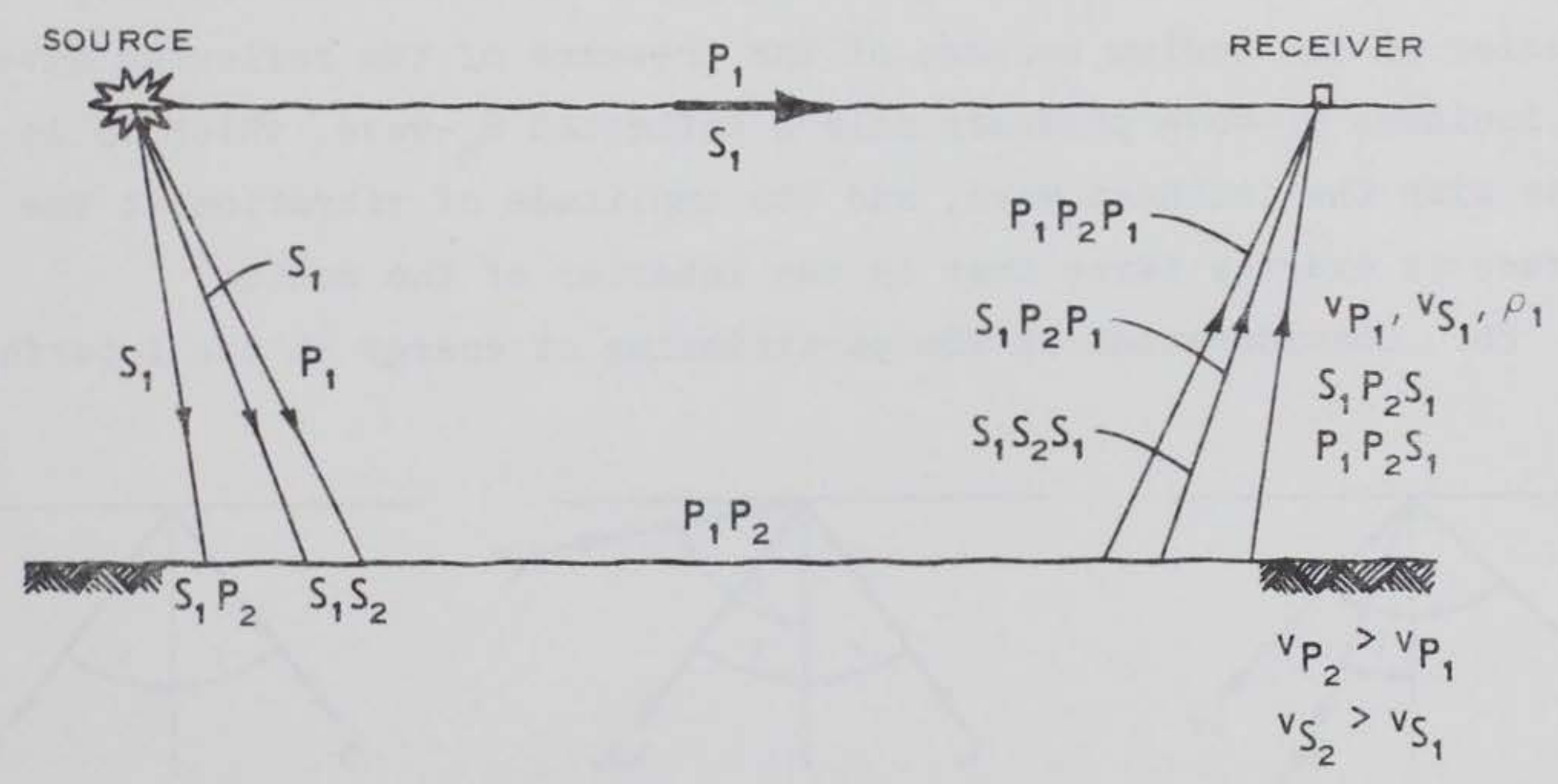

Figure 9. Ray paths for $\mathrm{P}-$ and $\mathrm{S}$-waves from source to receiver 
wave. There are three additional hypothetical combinations: $\mathrm{P}_{1} \mathrm{~S}_{2} \mathrm{~S}_{1}$, $\mathrm{P}_{1} \mathrm{~S}_{2} \mathrm{P}_{1}$, and $\mathrm{S}_{1} \mathrm{~S}_{2} \mathrm{P}_{1}$. However, in most real cases, we cannot draw ray paths for these rays because they are not critically refracted at the interface. Also present, but not shown in Figure 9, are the reflected ray paths $\mathrm{P}_{1} \mathrm{P}_{1}, \mathrm{P}_{1} \mathrm{~S}_{1}, \mathrm{~S}_{1} \mathrm{P}_{1}$, and $\mathrm{S}_{1} \mathrm{~S}_{1}$.

24. The governing equations for wave interaction at interfaces, as given by Ewing, Jardetsky, and Press (1957), show that, for angles of incidence smaller than the critical, the waves generated by the interaction at the interface are in phase with the incident wave. With angles of incidence greater than the critical angle, imaginary or complex coefficients arise in the governing equations, indicating changes of phase in reflected waves. These conditions imply that the direction of the first motion in waves arriving at the receiver after refraction through the underlying higher velocity medium should be the same as that in the waves following the direct path. This view considerably simplifies the interpretation problem.

25. The seismic wave incident at the free surface from below, as shown in Figure 10, produces only reflected waves at the boundary (interaction with the air is neglected). In general, the amplitude of the motion at the ground surface is greater than that in the deep interior of the medium because of the presence of the reflected waves. The incident $\mathrm{S}_{h}$-wave produces only a reflected $\mathrm{S}_{h}$-wave, which is in phase with the incident wave, and the amplitude of vibration at the surface is exactly twice that in the interior of the medium.

26. Consideration of the partitioning of energy at the interface

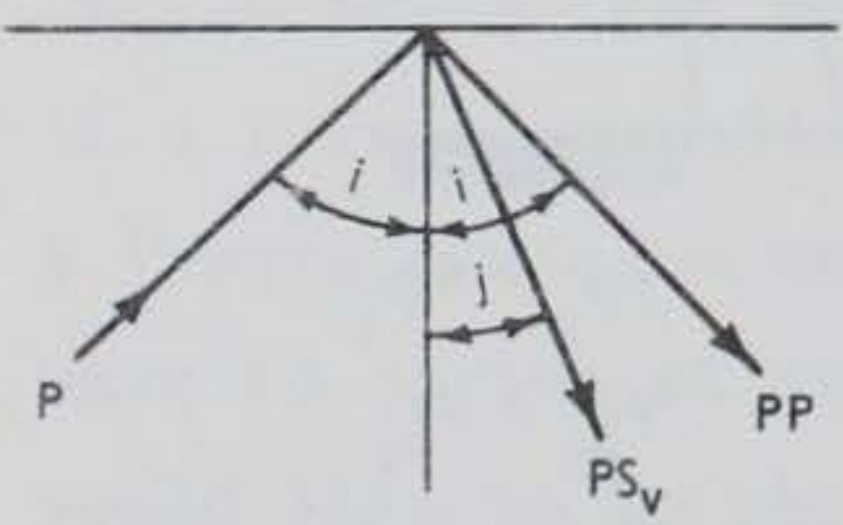

a.

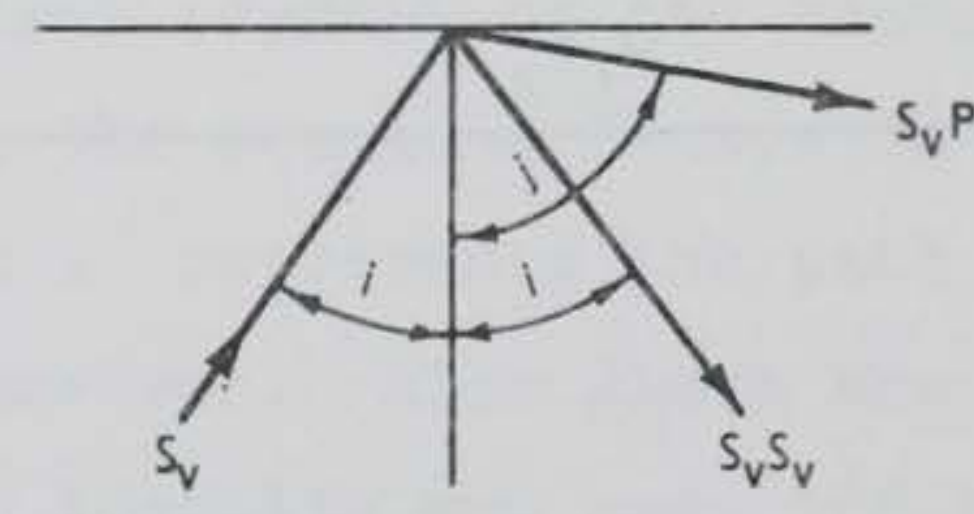

b.

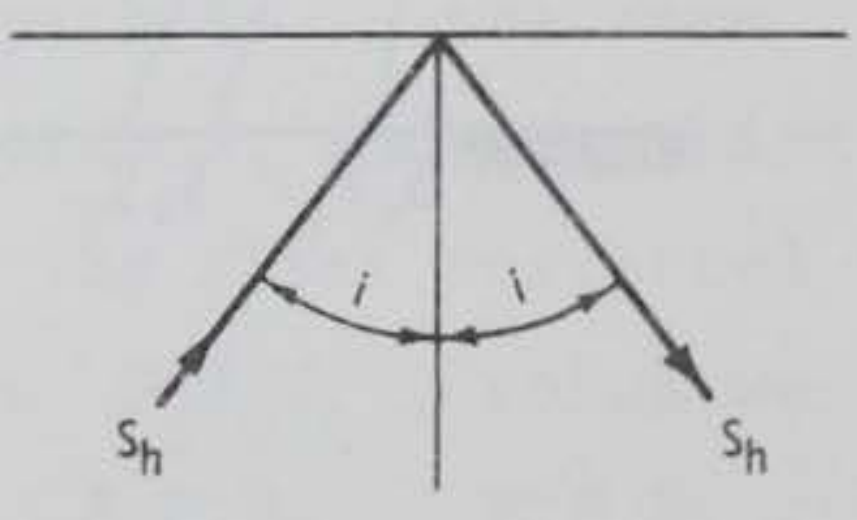

c.

Figure 10. Reflected waves at a free surface due to (a) an incident Pwave, (b) an incident $\mathrm{S}_{\mathrm{V}}$-wave, and (c) an incident $\mathrm{S}_{\mathrm{h}}$-wave 
between materials suggests that, if the objective of the survey is to investigate layer 2 by means of $S$-waves refracted in it, it would be best to use a seismic source that is rich in S-wave energy. Little Swave energy is induced in layer 2 by an incident P-wave. In addition, an $\mathrm{S}_{\mathrm{h}}$-wave theoretically produces no $\mathrm{P}$ - or $\mathrm{S}_{\mathrm{V}}$-wave energy at the interface, so that all of the energy is transmitted as $\mathrm{S}_{h}$-wave energy. Moreover, the motion at the receiver will be horizontal and so is easier to distinguish from the $\mathrm{P}$ - or R-wave than the vertical motion of an $\mathrm{S}_{\mathrm{V}}$-wave would be. In sumnary, theory indicates that the best method of exploring subsurface strata by means of refracted shear waves would be to use a shear wave source that produces only $\mathrm{S}_{\mathrm{h}}$-waves and to detect the signal with a horizontally polarized geophone oriented perpendicular to the line from source to geophone. 
27. Impulsive energy sources such as explosives, hammer blows, or falling weights are used almost exclusively for surface investigations. In principle, vibratory sources could be used to investigate P- and S-wave velocities, but interpretation of the records would require comparison of phase relations between the source and the detector, rather than the simple measurement of travel times, and thus would be more complicated. Steady state vibrations are sometimes used in investigations employing R-waves for exploration to limited depths (Ballard and McLean 1975).

28. Any energy source that produces $\mathrm{P}$-waves also produces $\mathrm{S}$-waves, and the S-waves can be detected by suitable directionally sensitive geophones. Explosions are the most symmetrical of the sources of seismic energy in common use, but even they yield considerable S-wave energy (Mooney 1974). A problem that arises in using such energy sources to observe $\mathrm{S}$-waves is that their arrival is often obscured by the P-wave train, which may contain confusing features such as arrivals of P-waves refracted or reflected from deeper horizons. Moreover, with a detector at the ground surface, the R-wave arrives soon after the S-wave, further complicating the wave train. The remedy for this problem is to use seismic sources that concentrate their energy in the S-wave, and preferably in an $\mathrm{S}_{\mathrm{h}}$-wave. The primary difficulty in applying this remedy is that designing of S-wave sources that are efficient in the transfer of the seismic energy into the ground has so far not been very successful.

29. The ideal $\mathrm{S}_{\mathrm{h}}$-wave source would have the following characteristics:

a. It would generate by impulse a pure $\mathrm{S}_{\mathrm{h}}$-wave with no $\mathrm{P}$ - or $\mathrm{S}_{\mathrm{V}}$-wave components.

b. It would produce a signal with a precisely controlled and adjustable energy content.

c. It would be precisely reversible, so as to produce antisymmetric wave forms upon alternate applications.

d. It would be light in weight and easily portable. The desirability of concentrating all the input energy in the $\mathrm{S}_{h}$-wave 
leads to the concept of a torsional source. Such a source might be envisioned as a rod embedded vertically in the ground, or a plate held in frictional contact with the ground, excited by a rotational impulse. The energy that can be transmitted into the ground by means of such a device is limited by the shear strength of the contact. At the present time, no practical torsional device for generating $\mathrm{S}_{\mathrm{h}}$-waves is available.

30. $\mathrm{S}_{\mathrm{V}}$-waves can be generated conveniently along with $\mathrm{P}$-waves by hammer blows or drop weights. Sources of this type for use at the ground surface are very simple. In boreholes, they can be applied through impacts on a rod resting on the bottom of the hole or a rod fixed by a packer to the wall of the hole (Ballard 1976). The energy that can be transmitted in the $\mathrm{S}_{\mathrm{v}}$-wave by impact at the bottom of the hole is limited by the shear strength of the soil and not that of the contact. $\mathrm{S}_{h}$-waves could be generated in a borehole by means of torsion applied to a packer device, but the shear strength of the contact would again control the energy that could be imparted in the $\mathrm{S}_{h}$-wave. No operational device of this type is known to the author.

31. An alternative to the torsional device for the generation of $\mathrm{S}_{\mathrm{h}}$-waves is a horizontal traction applied at the ground surface. The radiation pattern for an impulsive surface traction source is shown in Figure 11 (see Woods 1978). P- and $\mathrm{S}_{\mathrm{V}}$-waves are also generated by such a source and propagate most strongly in the direction parallel to the impulse. A nearly pure $\mathrm{S}_{\mathrm{h}}$-wave is propagated in a direction perpendicular to the direction of the impulse.

32. Until recently, the most common practice in surface $\mathrm{S}-$ wave surveys has been to use a shallow trench perpendicular to the line of the survey, with the seismic energy supplied by impact of a sledgehammer on a metal plate at an end of the trench. Auld (1977) describes a method, used for downhole S-wave velocity measurements, in which a 275-1b* weight, suspended as a pendulum, impacts against one side of a pit near the borehole. Attempts are sometimes made to provide greater

A table of factors for converting U. S. customary units of measurement to metric (SI) units is presented on page 3. 


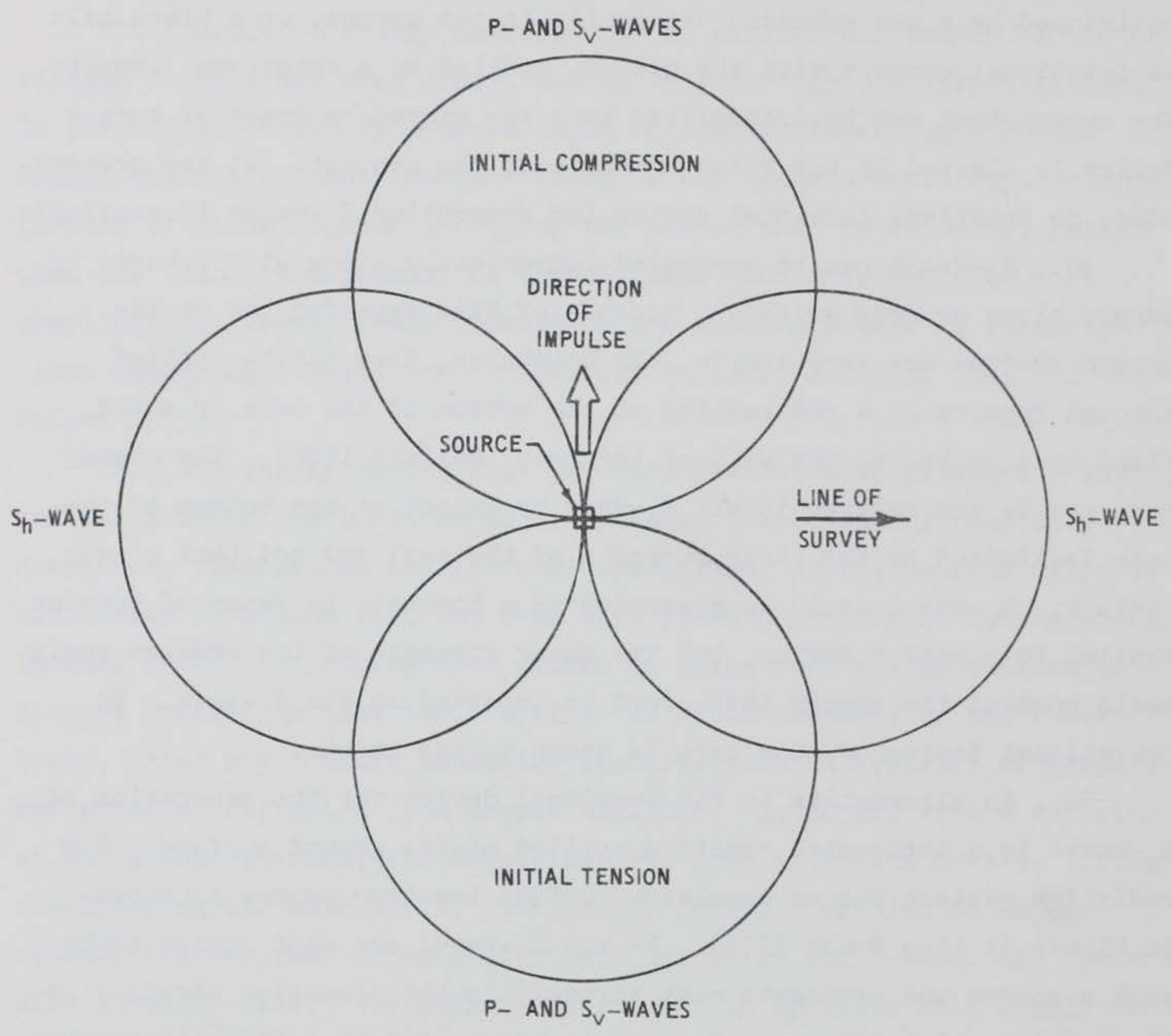

Figure 11. Radiation pattern for an impulsive surface traction source

energy by using an explosive charge at one end of the trench. Other devices using explosive charges include a type of water cannon, a 4-in.-diam military mortar (Woods 1978), and a distributed charge consisting of a helical coil of primacord on a wooden mandrel designed for use in a borehole (Martner and Silverman 1962).

33. Considerable success has been obtained with the use of a plank, usually of wood but occasionally of aluminum, held in frictional contact with the ground surface by a weight and struck at one end with a 
sledgehammer. The plank is usually weighted by the front wheels of an automobile or truck (see, for example, Power and Real 1976). In application of this technique at the Waterways Experiment Station (WES), it has been found that better signals are obtained with a smaller weight on the plank, and usual WES practice is to provide the surcharge by standing the wielder of the hammer on the plank. The method is illustrated in Figure 12. While the greater weight of a truck improves the coupling between the plank and the ground, it appears that the greater mass that has to be set in motion by the hammer blow results in a smaller net energy transfer into the ground. To reduce slippage between the plank and the ground, cleats consisting of common angle iron are attached to the bottom of the plank (Figure 13).

34. The plank and sledgehammer source, while generally providing signals of good quality, has some characteristics in which improvements are desirable. The energy that can be put into the $\mathrm{S}_{\mathrm{h}}$-wave is limited by the energy of the hammer impact and by the coupling between the plank

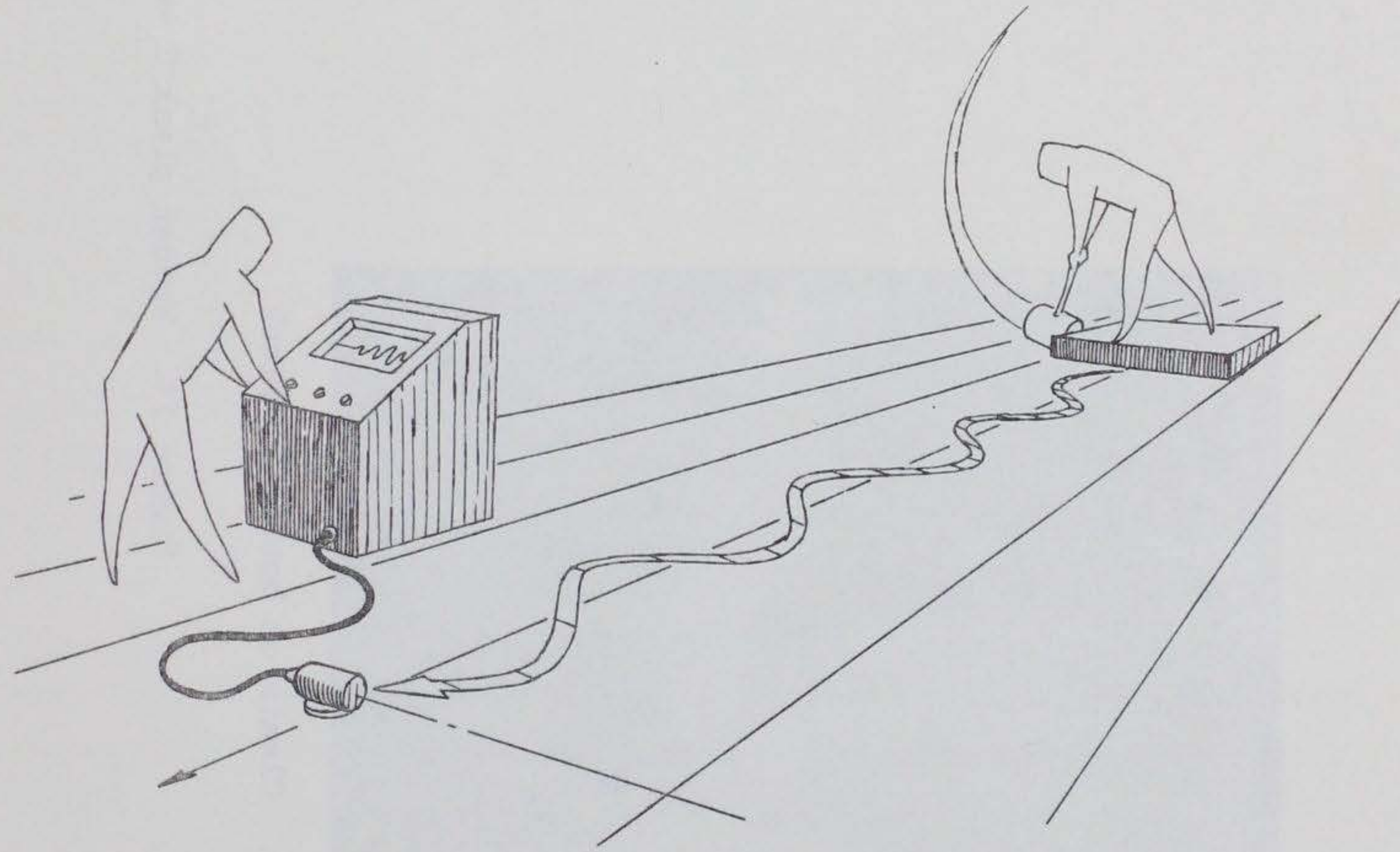

Figure 12. Refraction survey using a plank as an $\mathrm{S}_{\mathrm{h}}$-wave source 


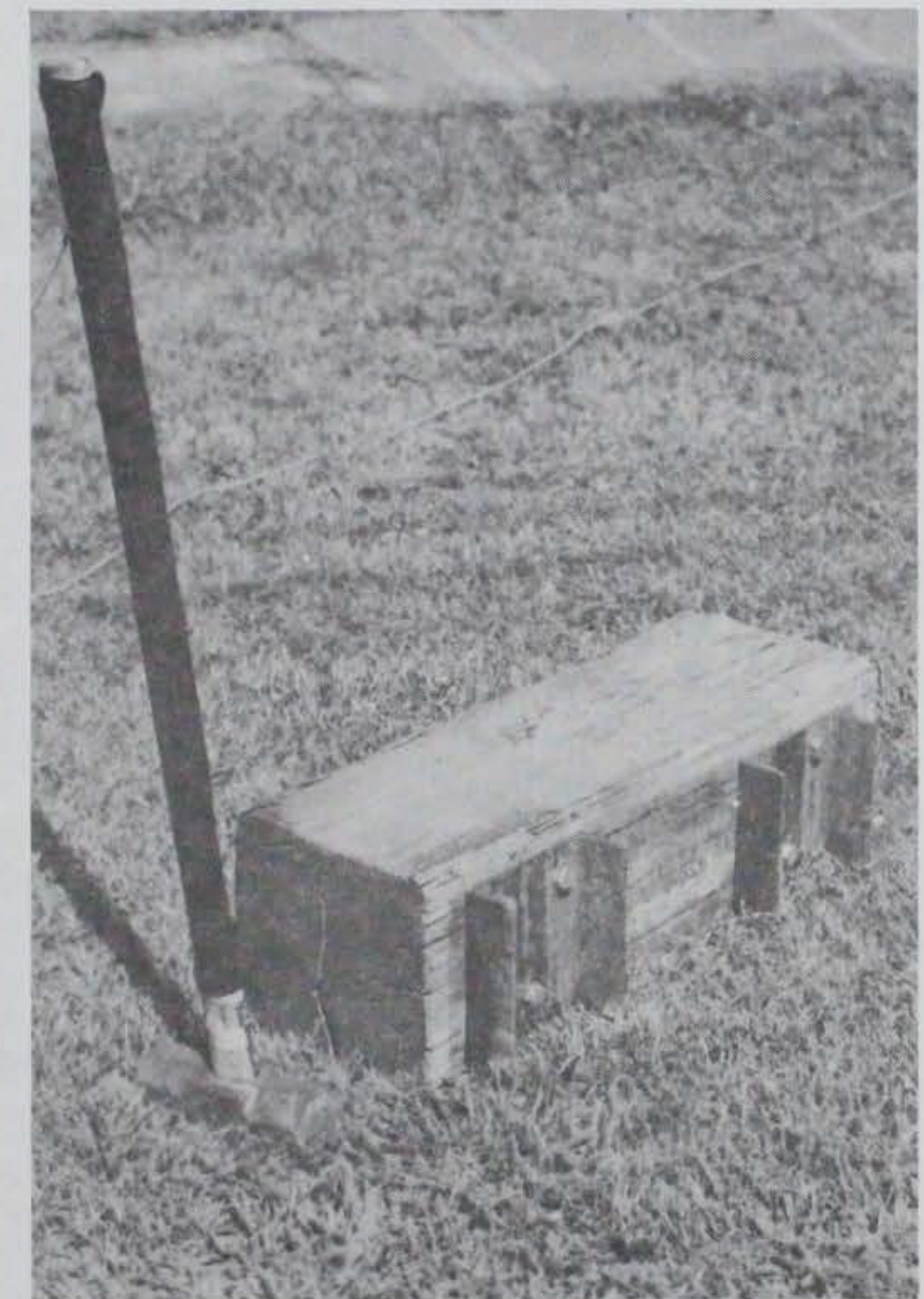

a. Cleats on bottom of plank

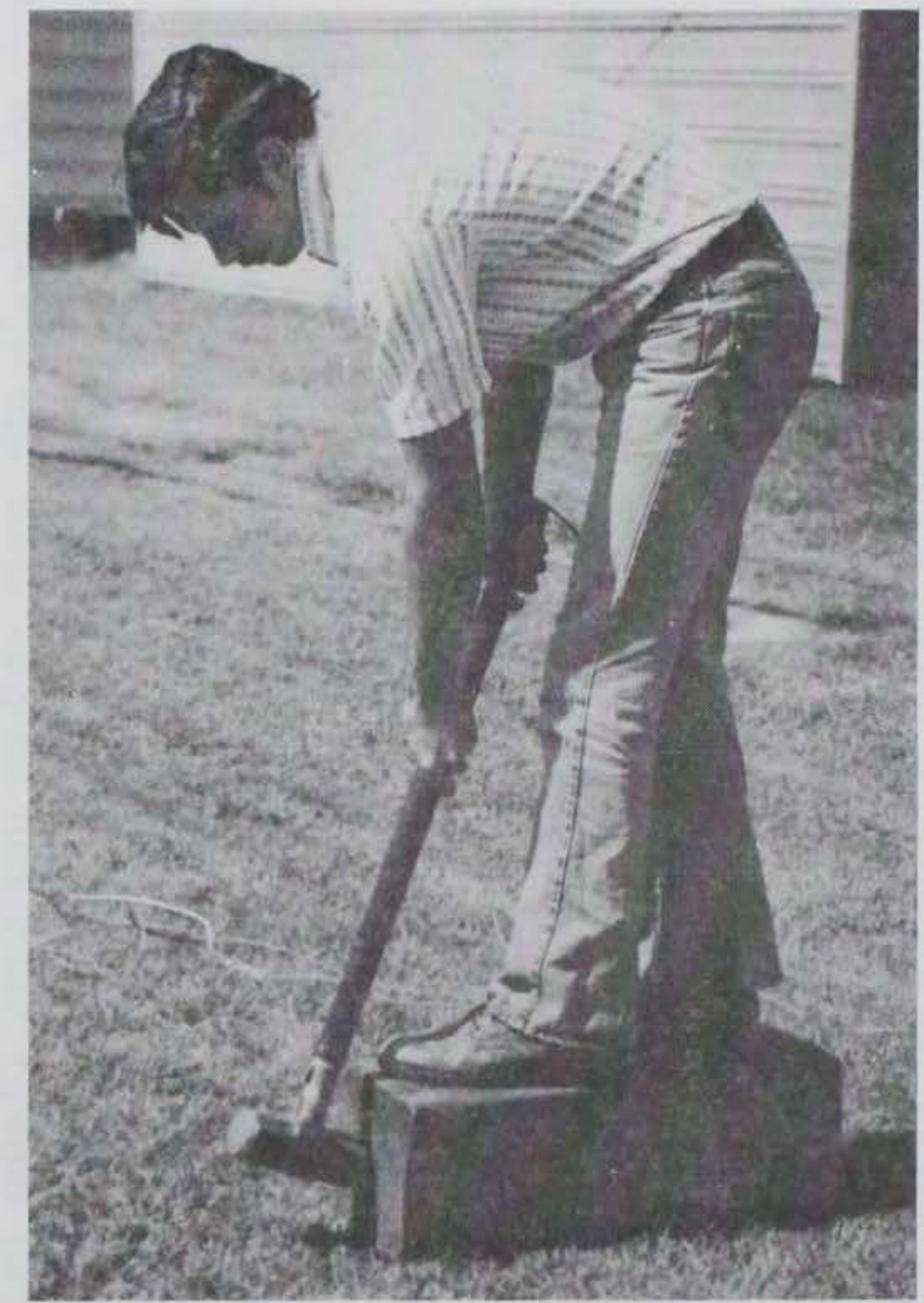

b. Use of plank with surcharge applied by hammer wielder

Figure 13. Wooden plank $\mathrm{S}_{h}$-wave source with cleats 
and the ground surface. In particular, where the ground surface is rock or hard soil, good coupling is difficult to obtain. These limitations on available energy mean that surveys cannot be extended over distances of more than about 100 to $200 \mathrm{ft}$, corresponding to depths of investigation of at most $50 \mathrm{ft}$. The impact of the hand-wielded hammer is not precisely aligned in direction or precisely repeatable either in direction or energy content. If there is a downward component in the hammer impact, unwanted $\mathrm{P}$ - and $\mathrm{S}_{\mathrm{V}}$-waves will be propagated along the line of survey. Also, an accidental component of the impact along the line of the survey, will produce $\mathrm{P}$ - and $\mathrm{S}_{\mathrm{v}}$-waves that propagate along the line of survey. The effect of these extraneous waves, if they are of sufficient amplitude, is to obscure the arrival of the $\mathrm{S}_{\mathrm{h}}$-wave. 
PART IV: DETECTION AND DISCRIMINATION OF $\mathrm{S}_{h}$-WAVES

35. In the interpretation of seismic records to obtain arrival times of the various wave types, the wave characteristics that are most useful for discrimination are: (a) the relative times of arrival, (b) the direction of particle motion, and (c) the phase relations between the recorded signal and the source. The relative amplitudes and frequency content of the various wave types may also be used to assist in their discrimination.

\section{Time of Arrival}

36. Of the various wave types that propagate in an elastic medium, the P-wave has the greatest velocity; therefore, if it is present, it is always the first to be detected at any geophone station. It is for this reason that methods of exploration using only the P-wave are so highly favored. Detecting the arrival of the P-wave requires only discriminating between the $\mathrm{P}$-wave arrival and the ambient noise, though accomplishing even this can present substantial difficulties under some conditions. The S-wave has the next highest velocity, followed closely by the R-wave. However, the S-wave arrival may be preceded by, or worse coincide with, one or more refracted or reflected P-wave arrivals. The R-wave velocity, in most cases, differs from the S-wave velocity by less than about 10 percent (Richart, Hall, and Woods 1970); at points near the source, it is usually difficult to distinguish the two.

\section{Direction of Particle Motion}

37. Because the different types of waves have distinctly different directions of particle motion, the directions may be used to discriminate between the waves. The $\mathrm{P}$-wave, if arriving over a direct path from the source, produces particle motions in the radial direction. A P-wave refracted from a subsurface interface will produce particle motions somewhere between the radial and vertical directions. Particle motion in the 
$\mathrm{S}_{\mathrm{v}}$-wave is always in the vertical direction, while that in the $\mathrm{S}_{\mathrm{h}}$-wave is horizontal and transverse to the path of wave propagation (perpendicular to the radial). In the $\mathrm{R}$-wave, particle motion is in a retrograde elliptical path so that both vertical and radial components of motion are present.

38. Using the direction of particle velocity for discrimination of wave types requires directionally sensitive geophones. Complete analysis requires records at each observation point from three orthogonally oriented geophones, and the processing of these records may be tedious. The same principle is used in the method of survey shown in Figure 12, in which a single geophone is oriented so that its axis is horizontal and transverse to the line of the survey. Since the $\mathrm{S}_{h}$-wave is the only one that produces motions in this direction, its identification should offer no difficulty. However, imperfection of alignment of the source or the geophone, or inhomogeneities of the soil, can produce motions in this direction that are actually caused by $\mathrm{P}$-waves. Normally, such P-wave motions should be of relatively small amplitude.

\section{Phase Relations}

39. In the context of the present discussion, the use of phase relations reduces to the consideration of the direction of the first motion in the wave of interest. For example, where the seismic energy source is an explosive, the first motion in the $\mathrm{P}$-wave is radially away from the source and the initial wave front is of compressive (as opposed to tensile) phase. Phase reversals may occur in reflected P-waves, depending on the nature of the P-wave velocity contrast at the interface. A P-wave reflected at a free surface is reversed in phase; that is, an incident $\mathrm{P}$-wave is reflected as a tension wave. On the other hand, a $\mathrm{P}$-wave incident at a rigid boundary is reflected without change of phase (Richart, Hall, and Woods 1970).

40. In an S-wave produced by an antisymmetric source, the direction of the first motion depends on the direction of motion of the source. The radiation pattern shown in Figure 11 applies in the case 
of the plank source of $\mathrm{S}_{h}$-waves. In both direct and refracted waves, the first motion of the $\mathrm{S}_{h}$-wave is in the same direction as the initial impulse. The first motions in the $\mathrm{P}-$ and $\mathrm{S}_{\mathrm{V}}$-waves are in opposite senses in the two primary directions of their propagation. If the hammer blow impulse to the plank has an accidental downward component, the first motion of the resulting $\mathrm{P}$-wave that will be propagated along the line of survey is in an outward radial direction. The initial motion in the resulting $\mathrm{S}_{\mathrm{V}}$-wave is downward. The consequences of these considerations are that the direction of first motion in the $\mathrm{S}_{h}$-wave should be reversed when the direction of the applied impulse is reversed, while the direction of first motion in $\mathrm{P}_{-}$and $\mathrm{S}_{\mathrm{v}}$-waves along the line of survey should not. Consequently, discrimination of the $\mathrm{S}_{h}$-wave from the $\mathrm{P}$-wave can be improved by interpretation methods that make use of the reversal of phase of the $\mathrm{S}_{h}$-wave. The hammer and plank source is used with a transversely oriented horizontal geophone as shown in Figure 12. Records are obtained using hammer blows alternately at opposite ends of the plank. If the two records are overlaid, the time of arrival of the $\mathrm{S}_{\mathrm{h}}$-wave is indicated by the divergence of the two traces. An example is shown in Figure 14.

41. Another technique for making use of the reversal of polarity for the discrimination of the $\mathrm{S}_{h}$-wave uses the "signal enhancement" feature found in a number of engineering seismograph units. The signal enhancement device samples the input from the geophone at very small time intervals (about $100 \mu \mathrm{sec}$ ) and stores the value of the signal amplitude for each time interval in a separate memory. The set of sampled values may be displayed on an oscilloscope as an amplitude versus time curve or may be recorded by a strip-chart recorder. Successive records, each of which begins with activation of an impact switch on the hammer, can be summed by adding the sampled amplitude values in each time inter$\mathrm{val}$, and the summed series of records is displayed as a single resultant amplitude versus time record. If the seismic signal is repeated and summed in this way several times, the repeatable parts of the signal build up to produce higher resultant amplitudes, while the noise, being random, has a tendency to cancel itself, or at least to build up much 
Signal trace from geophone $T$ - impact from north and of plank.

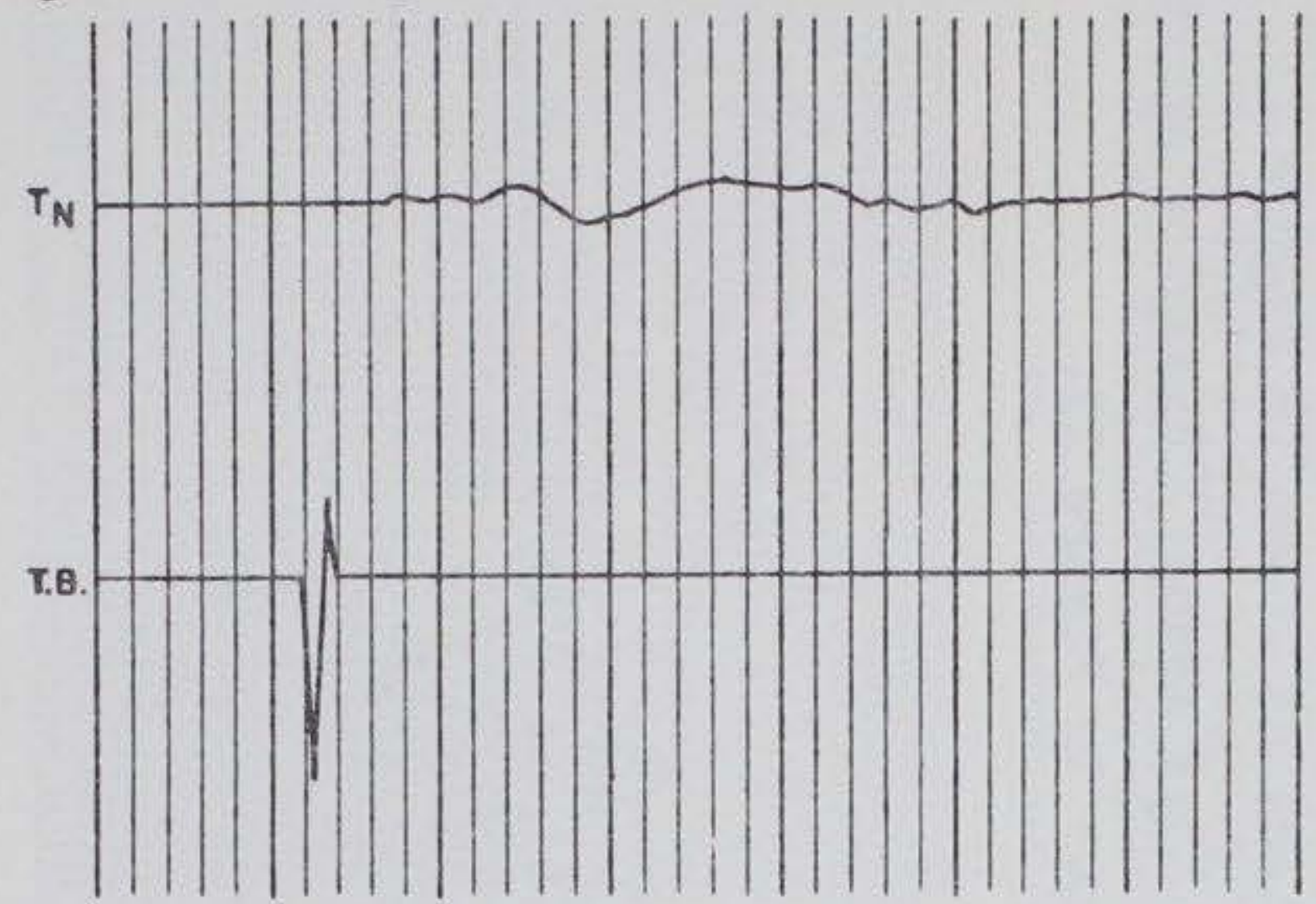

Signal trace from goophone T- impact from south and of plank.

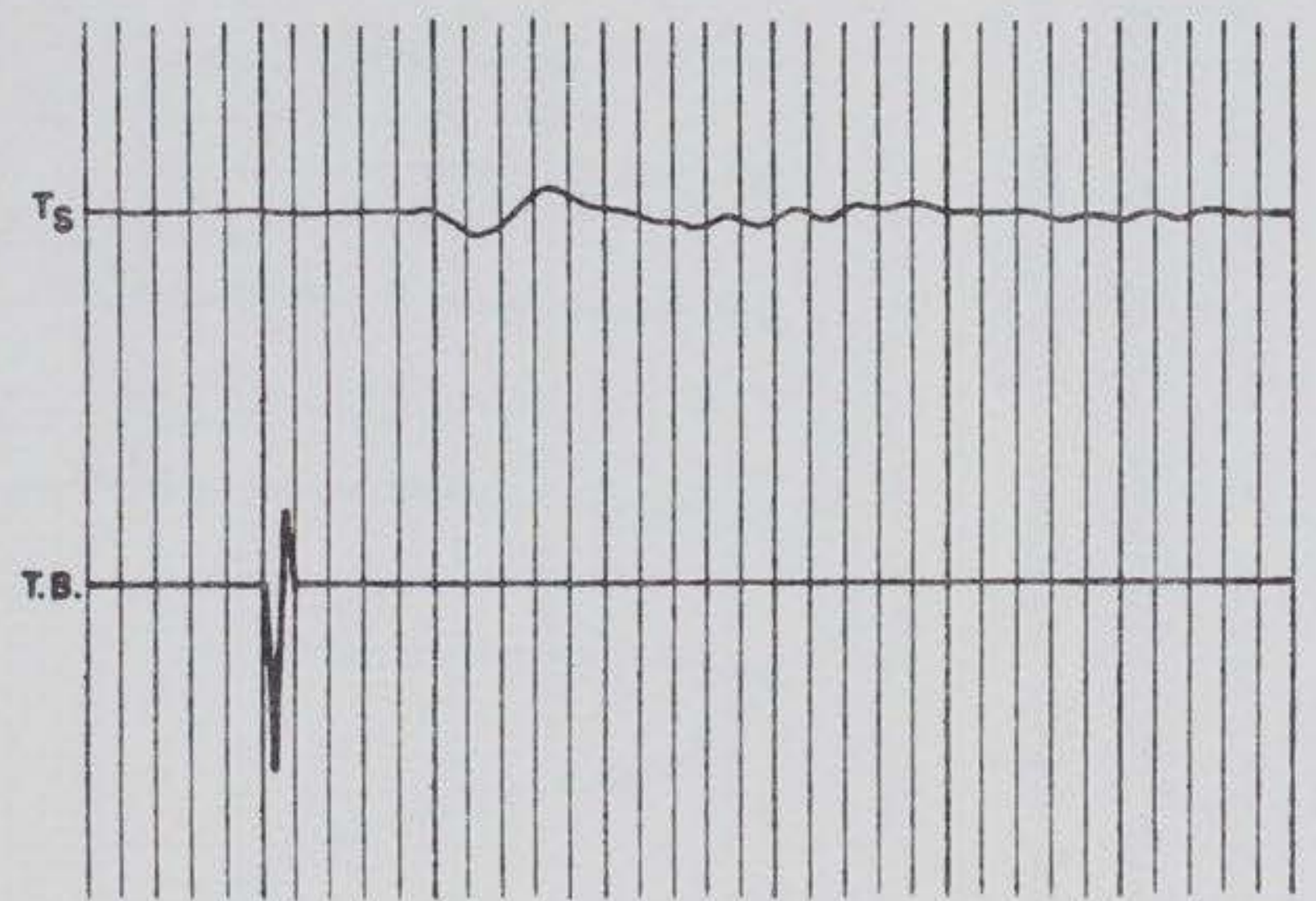

Signel traces frows seophone $T$ - north and south overiald.

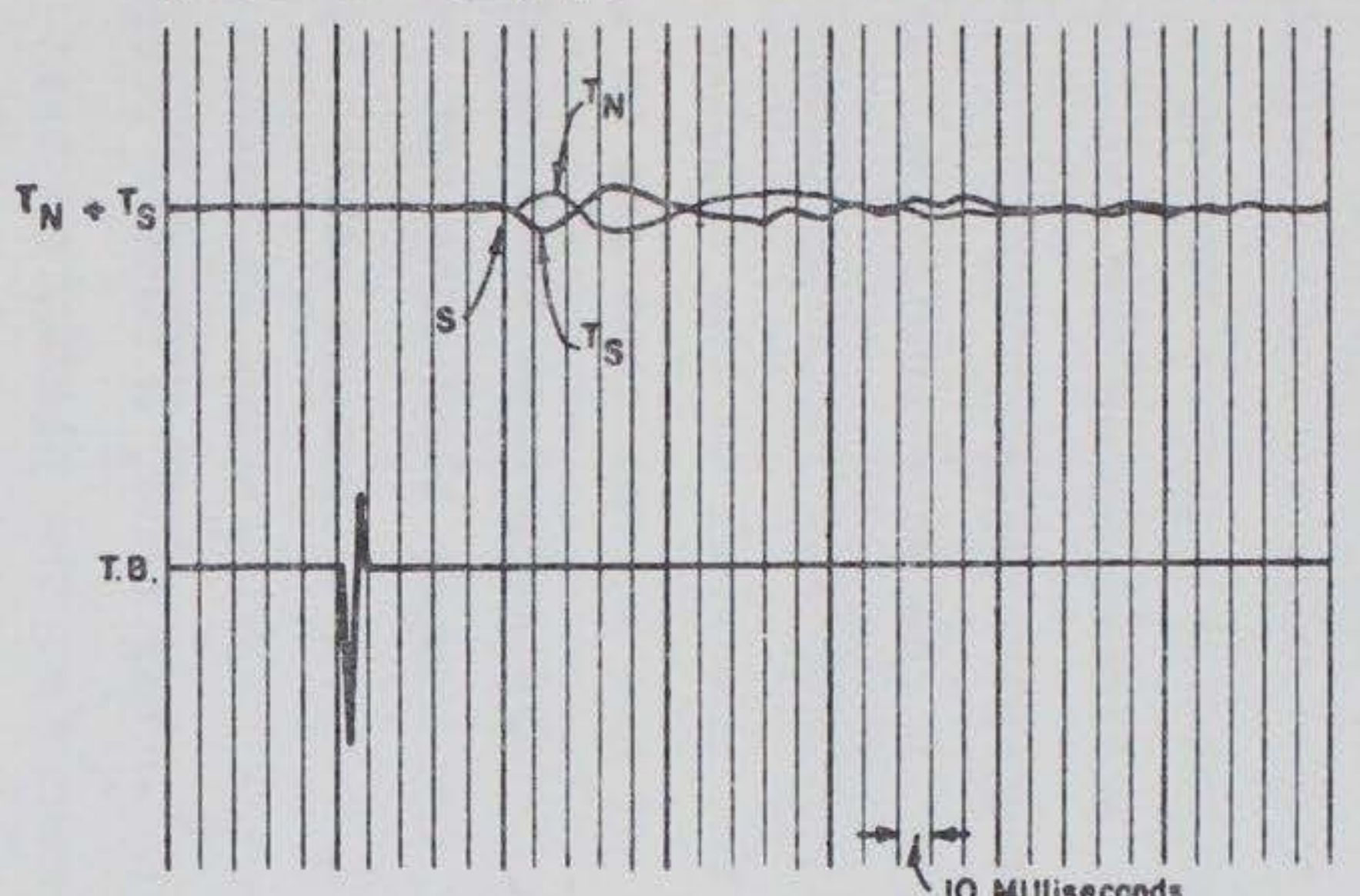

10 mulliseconds
LEGEND

T.B. = Time break or zero time, time of impact of hammer on plank. $T_{S}=$ Signal trace from horizontal geophone with the operational axis parallel to the plank - impact on the south end of plank.

$T_{w}=$ signal trace from horizontal geophone with the operationa axis parallel to the plank - impact on the north end of

8 s or Shear wave.

Figure 14. Identification of S-wave arrival by phase reversal in a downhole survey (after Viksne 1976) 
more slowly. The use of signal enhancement improves record quality in environments of high ambient noise or with seismic sources of low energy.

42. The signal enhancement device may be used in conjunction with a reversible S-wave source as follows: A polarity reversing switch is placed in the input line between the geophone and the seismograph, and the geophone polarity is reversed when the direction of the impulse on the source is reversed. Records from successive hammer impacts when summed in this way enhance those portions of the wave train that are reversed with reversal of the impulse direction and suppress those portions that do not change polarity with the reversal of the impulse, as well as noise and accidental components of the signal that are as likely to be in one direction as the other. A P-wave component that is caused by a consistently downward component of the hammer blow does not reverse and thus is suppressed on the record. A P-wave component caused by an accidental component of the blow transverse to the plank is random in phase and tends to be suppressed. On the other hand, a P-wave component of the record that is caused by misalignment of the plank, so that it is not exactly perpendicular to the line of survey, does reverse in polarity with reversal of the impulse direction, as shown in Figure 11, and cannot be eliminated from the record by this means. Examples of records obtained with signal enhancement are shown in Figure 15. 


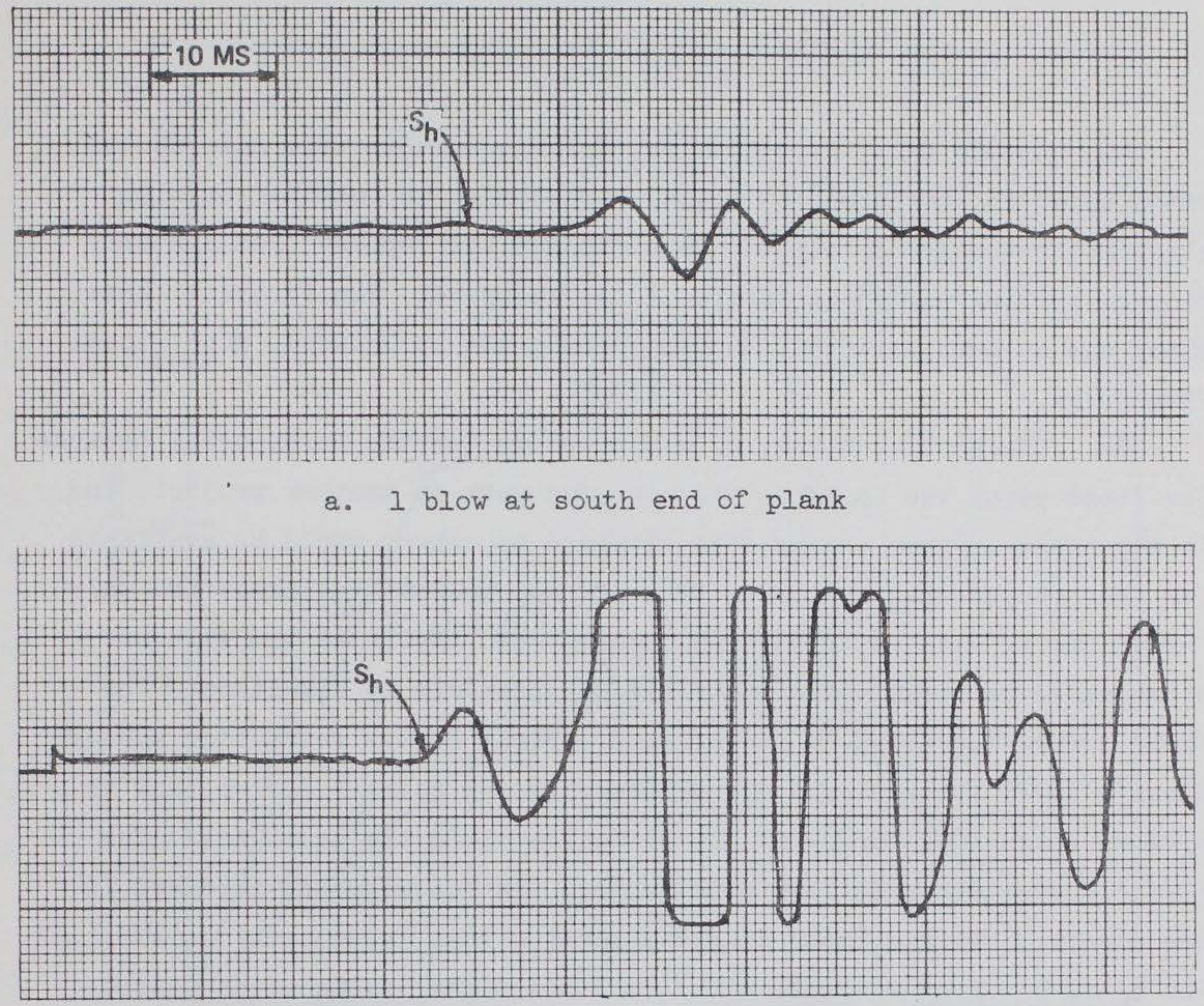

$$
\text { b. } 12 \text { blows at south end of plank }
$$

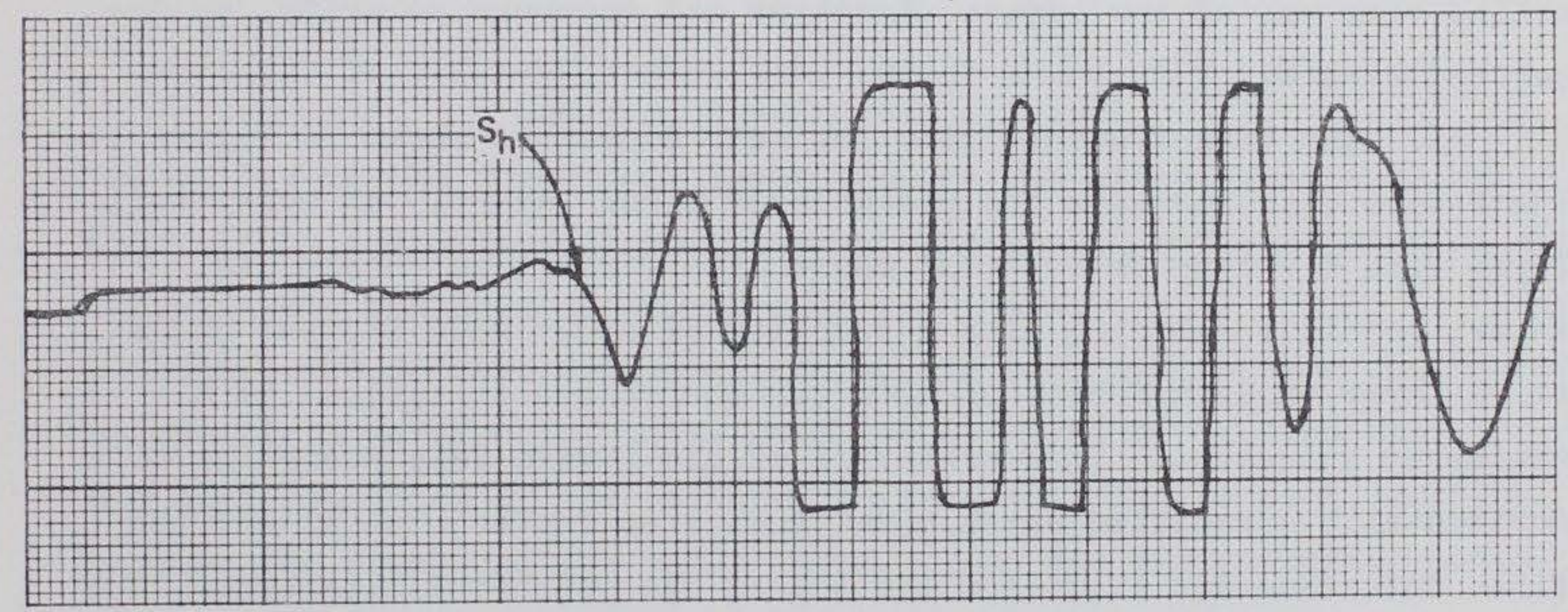

$$
\text { c. } 12 \text { blows at north end of plank }
$$

Figure 15. Example $\mathrm{S}_{\mathrm{h}}$-wave records obtained
with signal enhancement 


\section{PART V: FIELD STUDIES}

43. During this investigation, seismic surveys were made at two sites using the technique of signal enhancement in combination with alternate reversal of both the direction of the impulse from a hammer blow on a plank and the polarity of the geophone. The first of these sites was at Austin, Texas, and the second was at Redwood, Miss. (near Vicksburg).

44. The Austin, Texas, site was chosen for the first trial because the field party was to be at the site for work on another project, and it was expected that boring data obtained by others would be available for the site. However, boring data did not become available, and only P-wave survey data could be used for control. Soils at the site are unsaturated residual soils with caliche underlain by limestone. The field survey consisted of forward and reverse $P$-wave refraction surveys along a 55-ft line using a sledgehammer as the seismic source, and an $\mathrm{S}_{\mathrm{h}}$-wave refraction survey in one direction along the same line. The P-wave survey was made with a 24-channel SIE seismograph, repeated in one direction with a Bison single-channel signal enhancement seismograph. The $\mathrm{S}_{\mathrm{h}}$-wave survey was made with the Bison signal enhancement seismograph. The $\mathrm{S}_{h}$-wave source was a sledgehammer and plank, used with alternating reversal of the impact direction and geophone polarity, as described earlier.

45. The time-distance plot for this survey is shown in Figure 16. The P-wave data indicate the presence of three layers: an upper soil layer with a P-wave velocity of about $1100 \mathrm{ft} / \mathrm{sec}$; an intermediate layer, possibly caliche, with a velocity of about $2300 \mathrm{ft} / \mathrm{sec}$; and a third layer whose velocity of 5000 to $6000 \mathrm{ft} / \mathrm{sec}$ is typical of a weathered limestone. Interpretation of the P-wave data according to a horizontally stratified earth model indicates depths of $4 \mathrm{ft}$ for the first interface and $11 \mathrm{ft}$ for the top of the weathered limestone. The $\mathrm{S}_{\mathrm{h}}$-wave data indicate two layers: an upper layer with a $\mathrm{S}_{h}$-wave velocity of $440 \mathrm{ft} / \mathrm{sec}$, and the second layer with a velocity of about 2400 $\mathrm{ft} / \mathrm{sec}$. These S-wave velocities would be consistent with the P-wave 


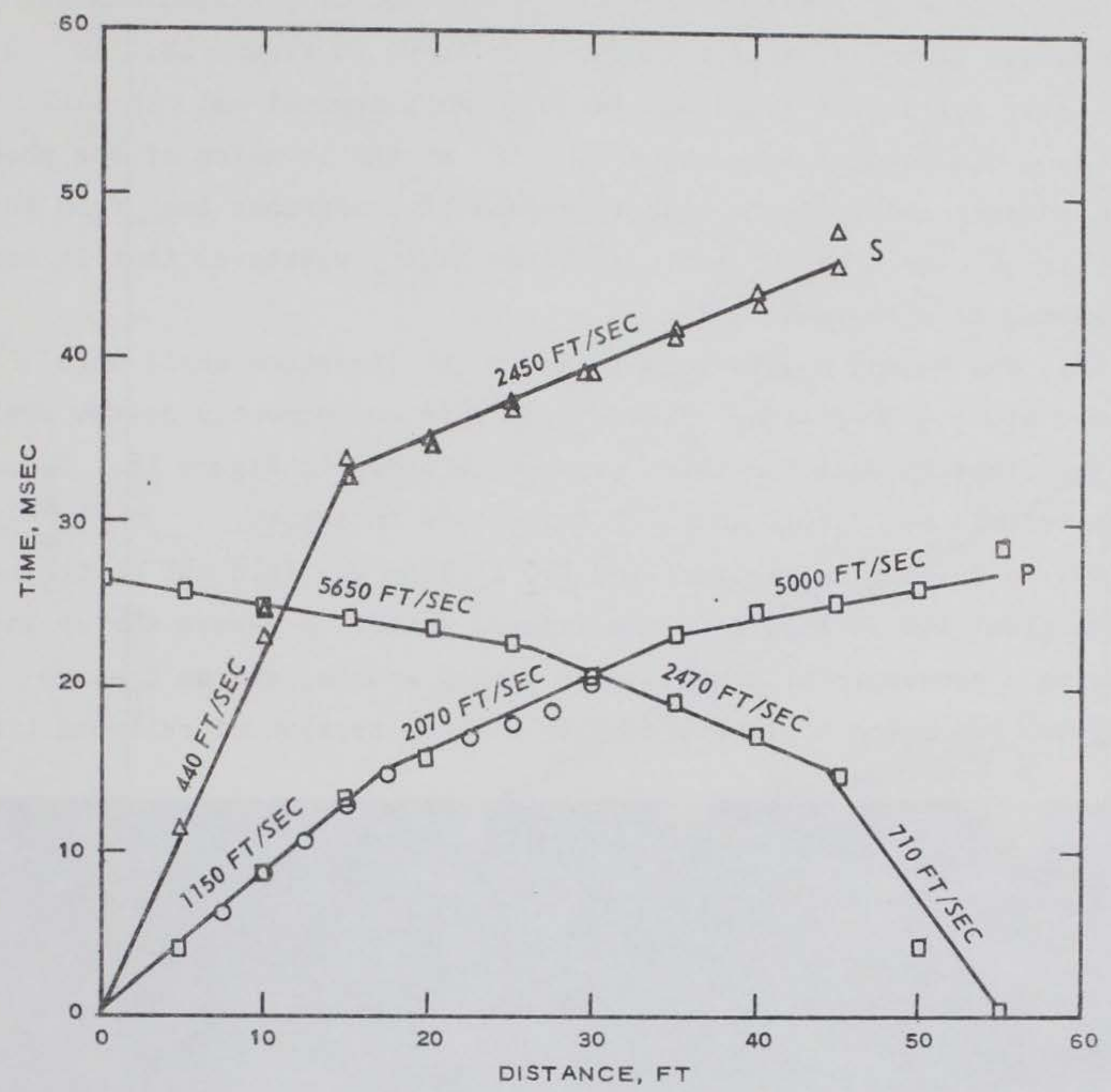

Figure 16. Time-distance plot for P- and S-wave refraction surveys, Austin, Texas, site

velocities of the upper soil layer and the weathered limestone, but there is no indication of the intermediate layer, so no meaningful depth calculations can be made from the $\mathrm{S}_{h}$-wave data.

46. The $\mathrm{S}_{\mathrm{h}}$-wave data obtained at the Austin site were considered by the field party chief to be unreliable. It was observed that the dry and hard condition of the sunbaked surface soil led to poor coupling between the plank and the soil. Also, there was heavy traffic noise from the nearby ( 600 to $800 \mathrm{ft}$ ) Interstate Highway 35 .

47. The same survey technique was applied at a second site, located in a quarry at Redwood, Miss. The quarry, now inactive, had been 
used as a source of limestone for the production of portland cement. A photograph of one side of the quarry is shown in Figure 17. An essentially horizontal limestone ledge is well exposed and the soil overburden has been stripped back so that, at the location of the photograph, a bench about $100 \mathrm{ft}$ wide is accessible. Farther back from the quarry is an overburden of marly shale so highly weathered that it can be regarded as a residual soil.

48. The $\mathrm{P}$ - and $\mathrm{S}$-wave velocities of the limestone shelf were measured along a 30-ft-long seismic line laid out directly on the shelf. The time-distance plot for these surveys is shown in Figure $18 . \mathrm{P}$ - and S-wave velocities of 6010 and $2720 \mathrm{ft} / \mathrm{sec}$ are indicated.

49. A seismic refraction line $140 \mathrm{ft}$ long was laid out on the soil surface about $100 \mathrm{ft}$ back from the exposed shelf. A P-wave survey was run using a conventional sledgehammer energy source, and an $\mathrm{S}_{\mathrm{h}}$-wave survey was run using a plank (actually a short section of railroad tie)

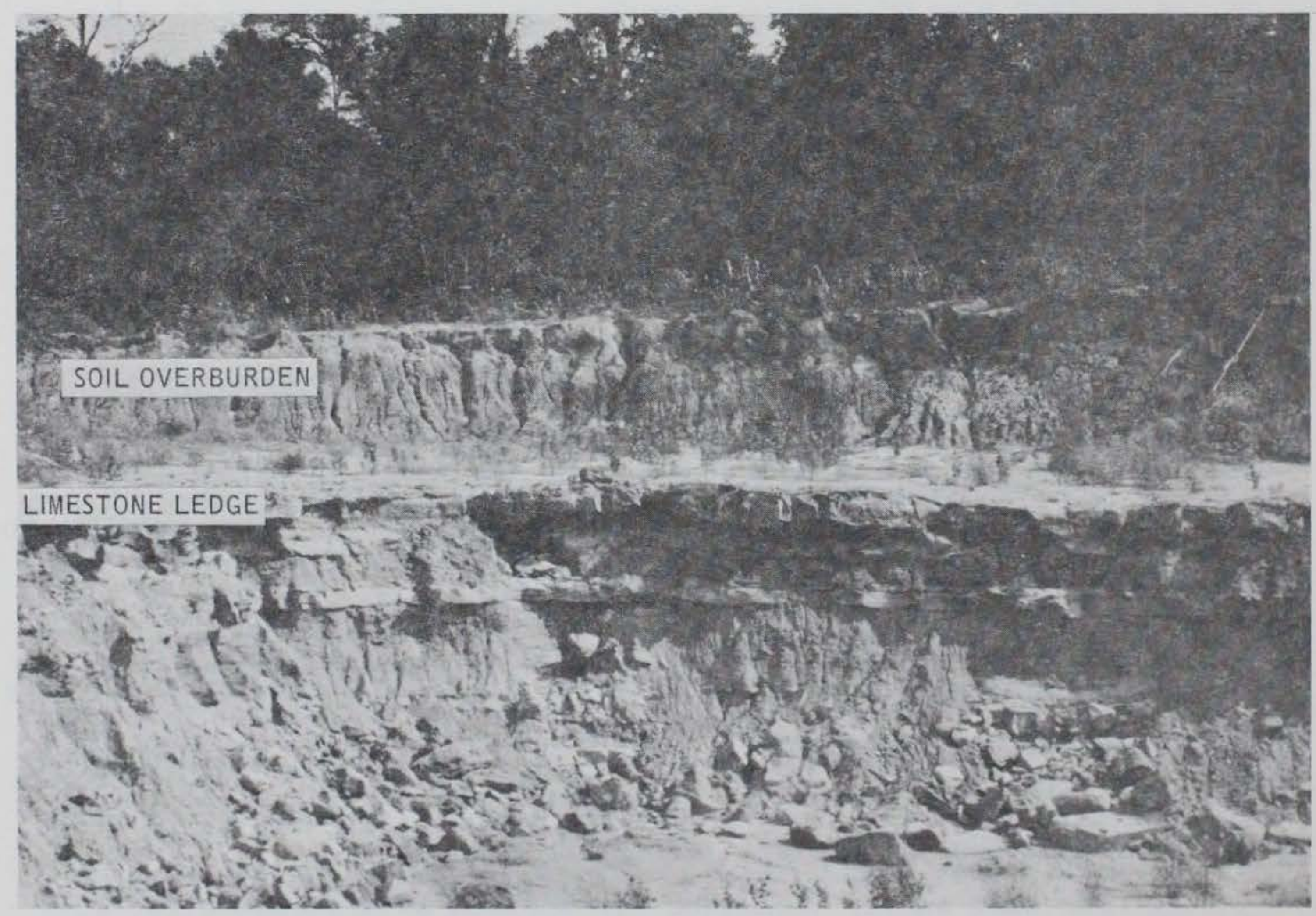

Figure 17. Bedrock exposure in quarry at Redwood, Miss. 


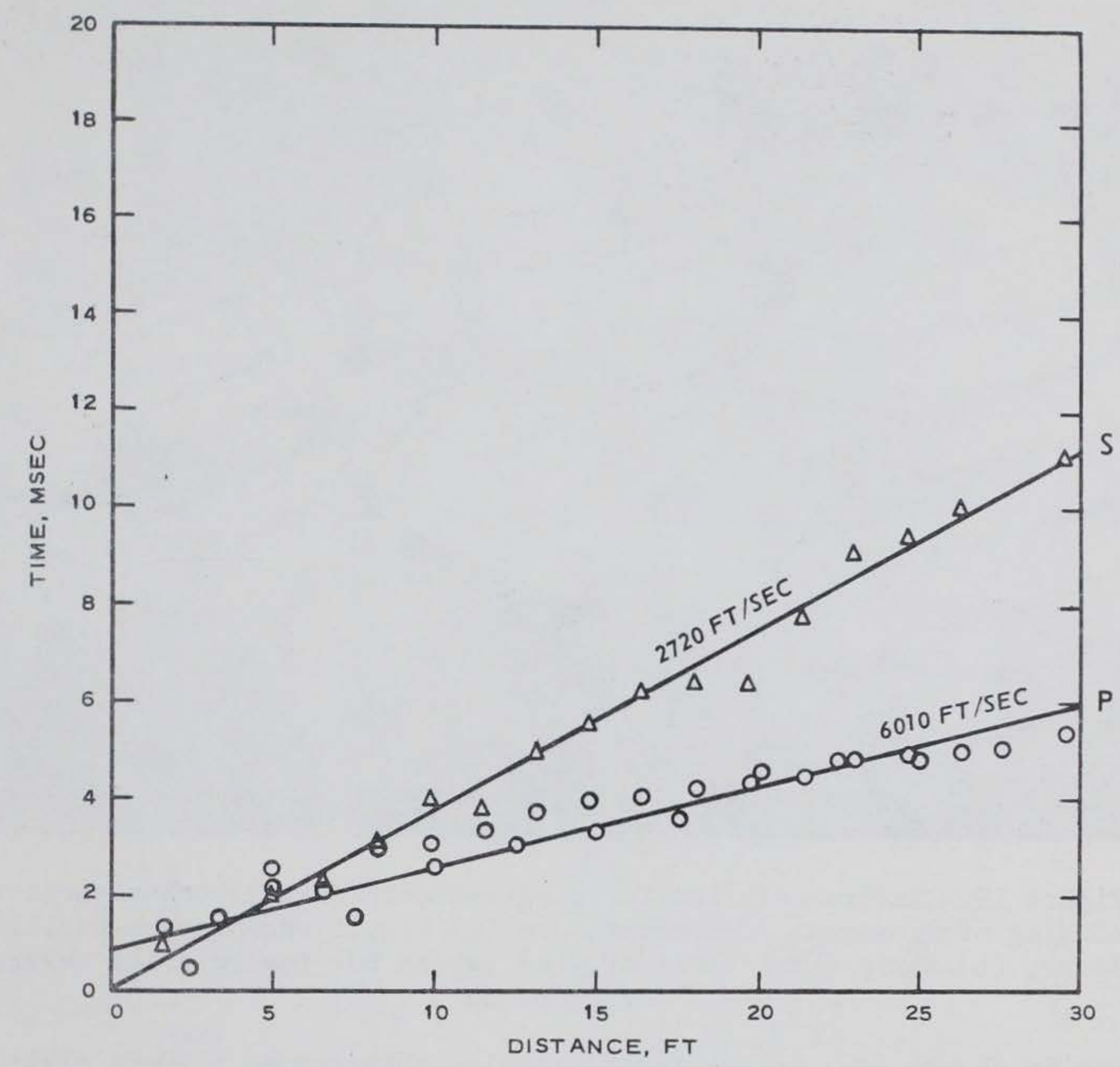

Figure 18. Time-distance plot for P- and S-wave velocity surveys on limestone ledge at Redwood, Miss., site

and sledgehammer, as previously shown in Figure 13. The $\mathrm{S}_{\mathrm{h}}$-wave records were obtained with a Bison single-channel signal enhancement seismograph and auxiliary strip-chart recorder (Figure 19). The ground surface along this line was gently sloping, and there was an elevation difference of a little less than $10 \mathrm{ft}$ between the ends of the line. Surveyed elevations showed that the limestone ledge was very nearly level and the thickness of the soil overburden varied between 10 and $20 \mathrm{ft}$ along the seismic lines. No elevation corrections were applied to the seismic data.

50. Examples of the records obtained in the $\mathrm{S}_{\mathrm{h}}$-wave surveys are 


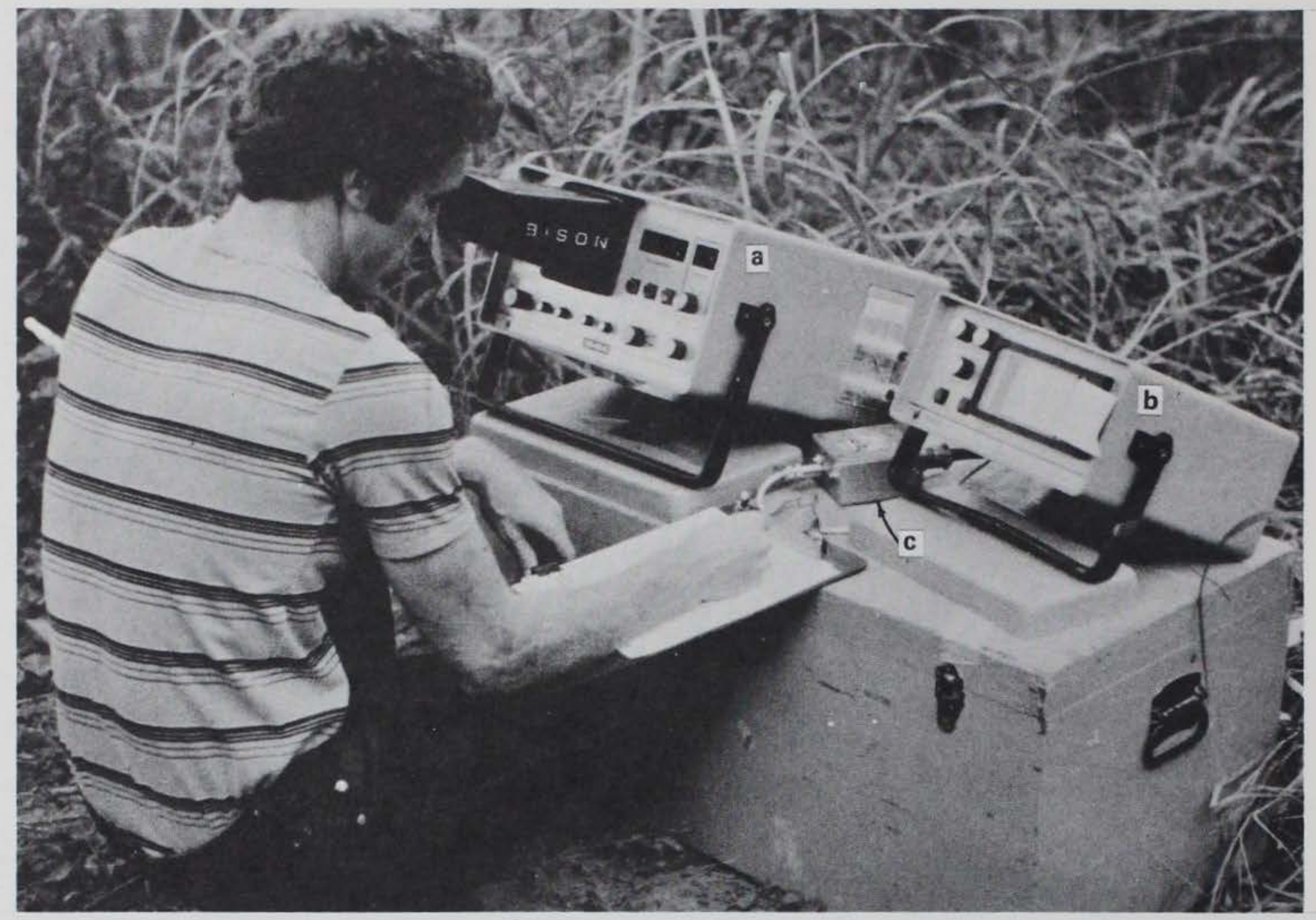

Figure 19. Instrumentation for single-channel signal enhancement recording of $\mathrm{S}_{\mathrm{h}}$-waves. Components are (a) signal enhancement oscilloscope, (b) strip-chart recorder, (c) switch box for polarity reversal of geophone

shown in Figure 20. In the first example, obtained at a 30-ft distance, the first $\mathrm{S}_{\mathrm{h}}$-wave arrival appears at $60.1 \mathrm{msec}$. A noticeable $\mathrm{P}$-wave component is present, appearing at $27.5 \mathrm{msec}$. The $\mathrm{S}_{h}$-wave arrival is identified as the beginning of the large excursion on the record. In the second example, obtained at a distance of $140 \mathrm{ft}$, the first arriving $\mathrm{S}_{\mathrm{h}}{ }^{-}$ wave, a refracted wave, arrives at $120 \mathrm{msec}$. It is identifiable as the beginning of the first significant excursion; the pattern in the earlier part of the record appears to be noise. In the field, the interpretation of records such as these is also aided by observing the growth or decay of the wave forms with repeated blows and polarity reversal and by consideration of the trends in arrival times with distance.

51. The time-distance plot for both $\mathrm{P}-$ and $\mathrm{S}_{\mathrm{h}}$-wave surveys is shown in Figure 2l. The arrivals shown in Figure 20 are identified on 


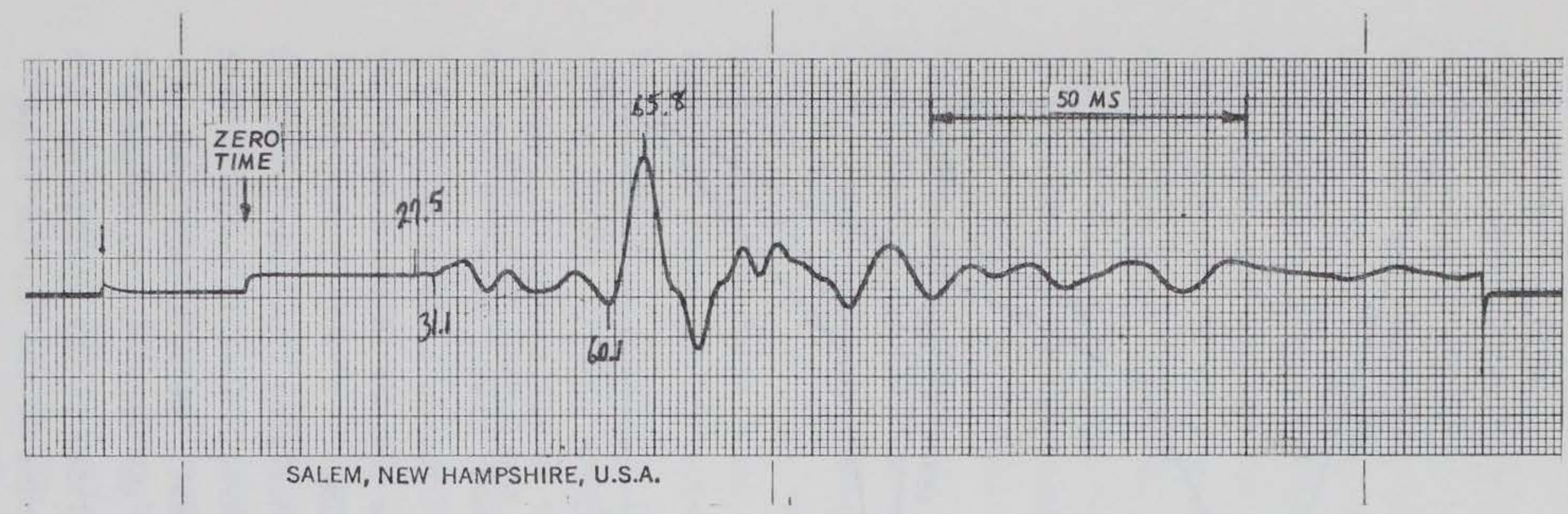

a. 30-ft distance, 3 blows in each direction

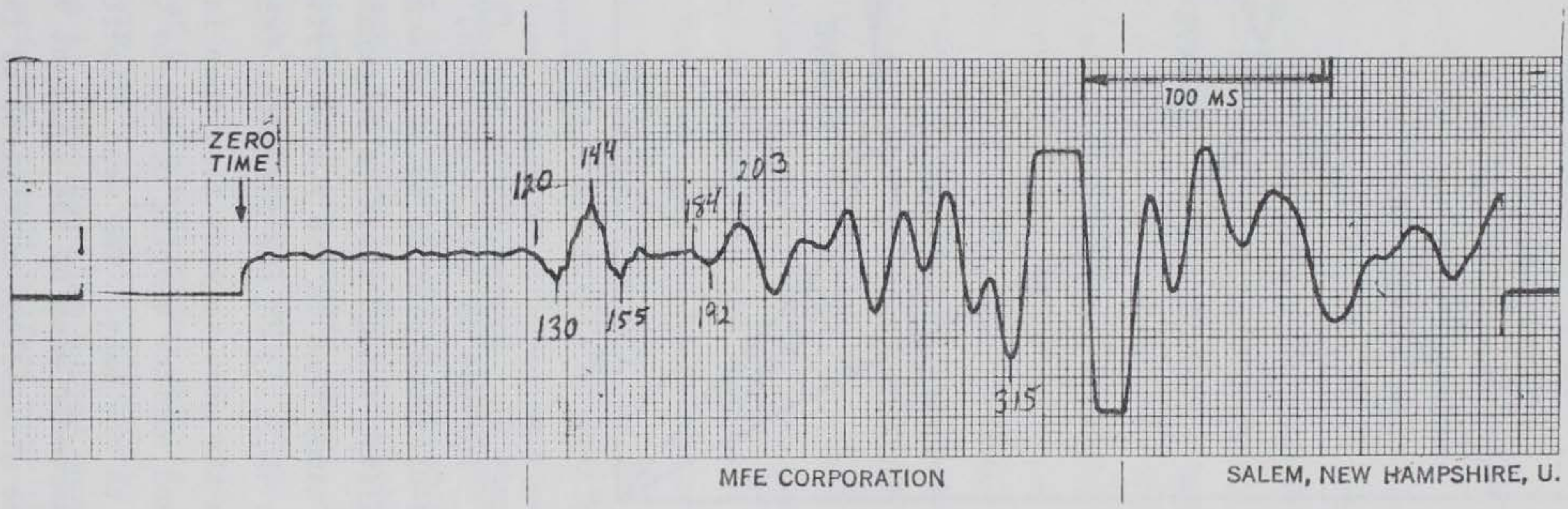

b. 140-ft distance, 8 blows in each direction

Figure 20. Signals obtained by signal enhancement seismograph from plank seismic source with alternate reversals of impulse direction and geophone polarity 


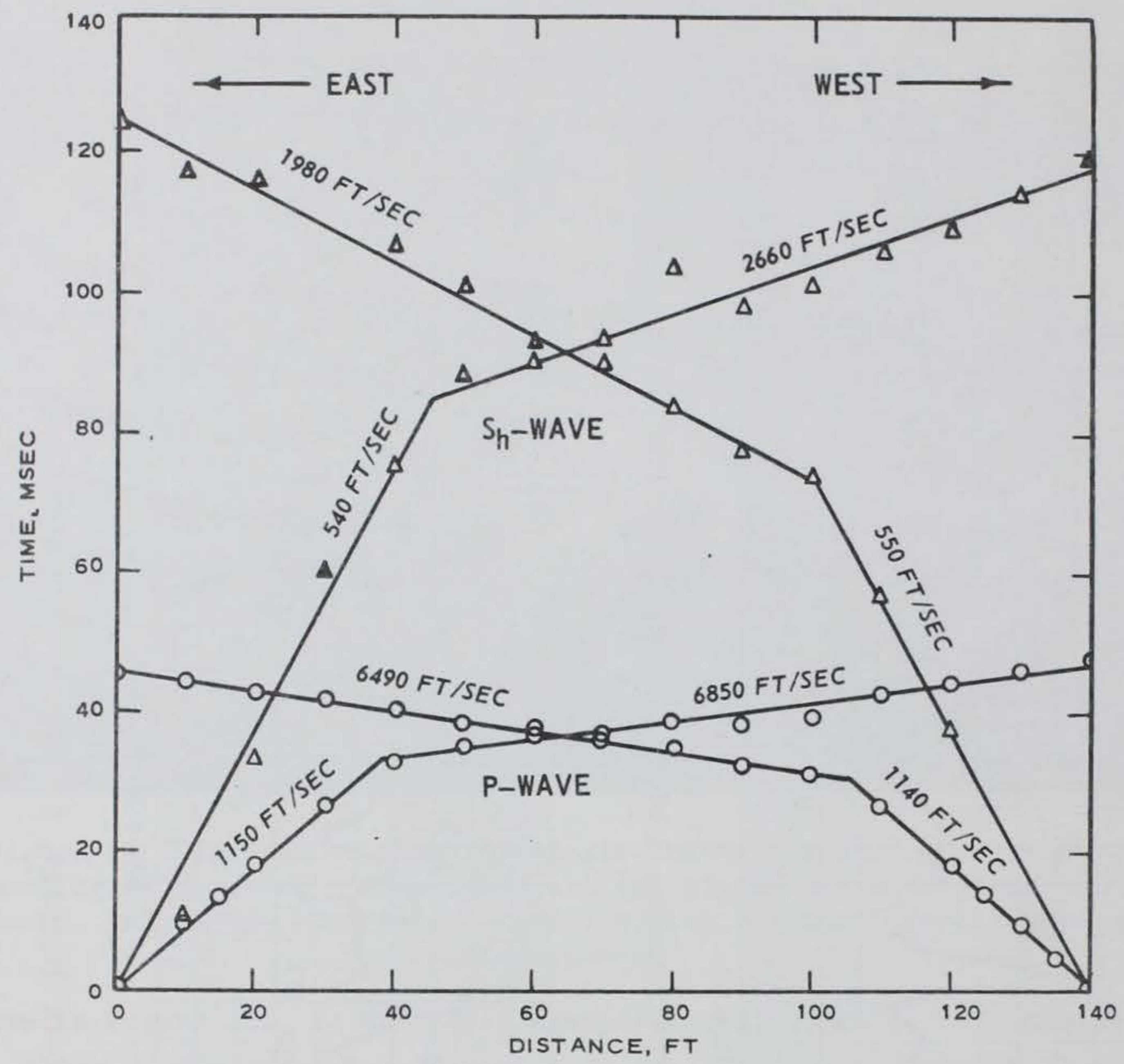

Figure 21. Time-distance plot for $\mathrm{P}$ - and S-wave refraction surveys on soil overburden, Redwood, Miss., site

the time-distance plot as solid triangles. The data appear to be of good quality, though there is somewhat more scatter in the S-wave arrival times than in the P-wave arrival times. In both plots, the apparent velocity of the refractor (the underlying limestone ledge) is lower in the west to east line than in reverse. This is because, with the ground surface sloping upward to the east, the soil thickness is greater to the east. The true velocity of the refractor is computed as the harmonic mean of the apparent velocities in the upslope and the downslope directions, multiplied by the cosine of the dip (or slope) angle (Redpath 1973) 


$$
v=\frac{2 v_{u} v_{d}}{v_{u}+v_{d}} \cos \delta
$$

where $v$ is the true velocity of the refractor, $v_{u}$ the apparent velocity in the updip direction, $v_{d}$ the apparent velocity in the downdip direction, and $\delta$ is the dip angle (in this case, the angle between the plane of the ground surface and the plane of the refracting horizon). This yields an S-wave velocity of $2270 \mathrm{ft} / \mathrm{sec}$ and a P-wave velocity of $6670 \mathrm{ft} / \mathrm{sec}$ for the limestone ledge. For the soil overburden, an S-wave velocity of $545 \mathrm{ft} / \mathrm{sec}$ and a $P$-wave velocity of $1145 \mathrm{ft} / \mathrm{sec}$ are indicated. The depth of overburden is computed as $15.7 \mathrm{ft}$ from the P-wave plot and $16.3 \mathrm{ft}$ from the S-wave plot; the difference is within the range of uncertainties in the computation.

52. It was noted again at the Redwood site, during the S-wave survey on the limestone shelf, that the coupling between the plank and the hard limestone surface was not entirely satisfactory, although adequate S-wave signals were received out to a distance of $30 \mathrm{ft}$. This problem did not occur on the soil overburden. It was observed that precisely repeatable wave forms could not be obtained with the hand-held hammer since the force and direction of the blow, as well as the nature of the impact (angle of incidence between the hammer head and the end surface of the plank, rebound, secondary impacts, and effects of wear and unevenness of the surface of the plank) could not be precisely controlled. An additional, and unexpected, problem was that there appeared to be a slight difference in the response time of the geophone depending on the direction of first motion. However, measures to overcome these problems (anchoring of the source, mechanization of the hammer impact, improved. control of geophone characteristics) would appear to be easily achievable refinements of the technique.

53. An additional example of $\mathrm{S}_{\mathrm{h}}$-wave refraction data is shown in Figure 22. The data shown here are part of those obtained for the seismic analysis of Alben Barkley Dam in Kentucky. The survey shown was made along a 600-ft line on the original ground surface near the downstream toe of the dam. The $\mathrm{S}_{h}$-wave data were obtained only along a 


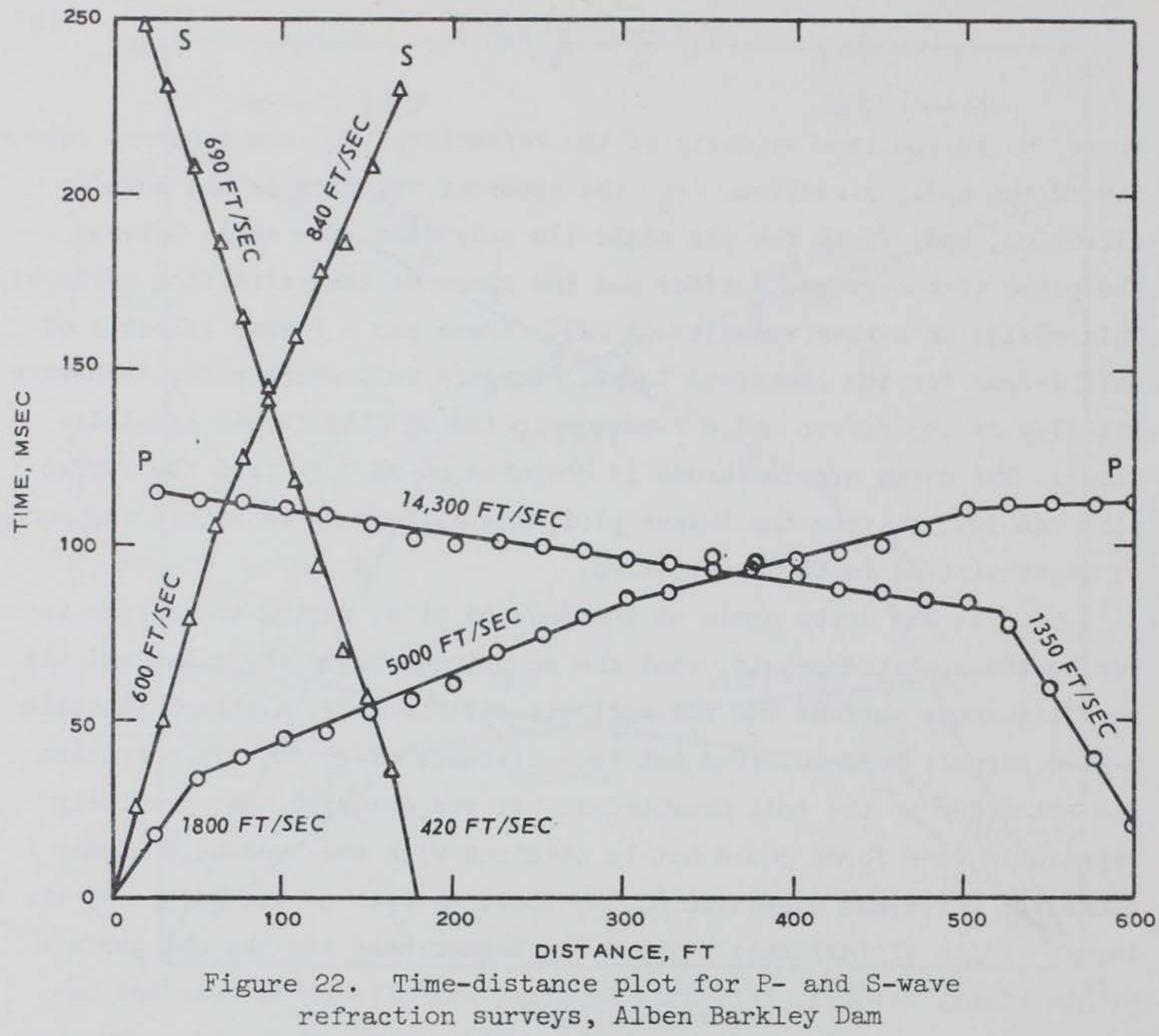

180-ft segment of the line. The foundation at the site consists of a layer of alluvial lean clay approximately $9 \mathrm{ft}$ thick, underlain by alluvial silts and sands, and finally limestone bedrock which contains cavities in some areas. The P-wave data were obtained with an explosive source and a 24-channel seismograph unit. The $\mathrm{S}_{h}$-wave data were obtained with a plank and hammer as the source and the same 24-channel seismograph unit, on which signal enhancement is not available. $\mathrm{S}_{h}$-wave records were obtained from hammer impacts on each end of the plank, and the $S_{h}$-wave arrival time was determined by the time of phase reversal, as illustrated in Figure 14.

54. The P-wave plot for this line indicates a subsurface 
configuration of some complexity. The forward line indicates a surface layer with a P-wave velocity of $1800 \mathrm{ft} / \mathrm{sec}$, an underlying layer with a P-wave velocity of $5000 \mathrm{ft} / \mathrm{sec}$, and one or two additional layers of higher velocity, somewhat uncertain in value. The reverse line indicates a surface layer with a P-wave velocity of $1350 \mathrm{ft} / \mathrm{sec}$ and a second layer with a velocity of 14,330 ft/sec, clearly representing the underlying limestone bedrock in a relatively unweathered condition. The $\mathrm{S}_{\mathrm{h}}{ }^{-}$ wave velocity plot indicates a surface layer with an S-wave velocity of about $500 \mathrm{ft} / \mathrm{sec}$ and an underlying layer with an S-wave velocity of about $760 \mathrm{ft} / \mathrm{sec}$. Both of these velocities are evidently associated with layers of the soil overburden, and the line is not sufficiently long to indicate S-wave returns from the limestone. Further description of the foundation conditions is given by Marcuson and Golden (in preparation). 
55. The studies described in this report show that it is feasible to use refracted shear waves for the investigation of subsurface strata, at least to limited depths and under favorable conditions. A refraction survey made in the course of this investigation produced good S-wave data from a depth of $16 \mathrm{ft}$ at a site where there was a strong velocity contrast between the bedrock at that depth and the overburden soil. So far in these studies, records of refracted S-waves clearly showing more than one subsurface layer interface have not been obtained. The most serious limitation in the present state of the art appears to be that currently available S-wave sources are severely limited in the strength of the S-wave signal they can apply. The effect of this limitation is to impose limits on the length of the line over which a signal can be detected and therefore on the effective depth of investigation.

56. Theoretical considerations as well as experience indicate that $\mathrm{S}_{\mathrm{h}}$-waves are the best type of signal to use in $\mathrm{S}$-wave surface refraction surveys. The $\mathrm{S}_{\mathrm{h}}$-wave is easier to distinguish from the P-wave than is the $\mathrm{S}_{\mathrm{v}}$-wave. Also, there is less energy lost through conversion to $\mathrm{P}$-waves at interfaces between layers. Where anisotropy of S-wave velocity is of concern, separate measurements of $\mathrm{S}_{\mathrm{h}^{-}}$and $\mathrm{S}_{\mathrm{V}}$-wave velocities should be made. Surface traction applied through hammer blows against a plank has proved to be a good source of $\mathrm{S}_{\mathrm{h}}$-wave energy.

57. The use of phase reversal in the $S_{h}$-wave with reversal of the impulse direction in the source is a valuable aid in improving discrimination between the $\mathrm{S}_{\mathrm{h}}$ - and $\mathrm{P}$-waves. This may be done by superimposing and comparing signals obtained with reversed directions of impulse in the source or with the aid of a signal enhancement seismograph with alternating reversal of both source motion and geophone polarity in order to enhance the $\mathrm{S}_{\mathrm{h}}$-wave and suppress both $\mathrm{P}$-wave and noise components. However, these methods depend on the reversibility and repeatability of the $\mathrm{S}_{h}$-wave signal. The $\mathrm{S}_{h}$-wave source in most common use at the present time--the plank subjected to hammer impacts at the ends-is not entirely satisfactory with respect to its repeatability. It 
would be desirable to develop a modification of the plank source that would provide better control of the energy content and repeatability of the input as well as the coupling between the source and the ground surface, while maintaining easy portability of equipment.

58. Where S-wave surveys are performed, they should be done in conjunction with $\mathrm{P}$-wave surveys. The availability and use of P-wave travel time data greatly improve the interpretability of the S-wave data, assessment of the reliability of the data, and confidence in the interpretation. 
Auld, Bruce. 1977. "Crosshole and Downhole $V_{S}$ by Mechanical Impulse," Journal, ASCE, Vol 103, No. GT12, pp 1381-1398.

Ballard, R. F., Jr. 1976. "Method For Crosshole Seismic Testing," Journal, ASCE, Vol 102, No. GT12, pp 1261-1273.

Ballard, R. F., Jr., and McLean, F. G. 1975. "Seismic Field Methods for In Situ Moduli," Miscellaneous Paper S-75-10, U. S. Army Engineer Waterways Experiment Station, CE, Vicksburg, Miss.

Ewing, W. Maurice, Jardetzky, W. S., and Press, F. 1957. Elastic Waves in Layered Media, McGraw-Hill, New York.

Marcuson, W: F. III, and Golden, G. In preparation. "Dynamic Analysis of the Alluvial Foundation for Barkley Dam," U. S. Army Engineer Waterways Experiment Station, CE, Vicksburg, Miss.

Martner, S. T., and Silverman, D. 1962. "Broomstick Distributed Charge," Papers for the Field Geophysicist, Supplement to Geophysics, Vol XXVII, No. 6, Pt. 11 .

Mooney, Harold M. 1974. "Seismic Shear Waves in Engineering," Journal, ASCE, Vol 100, No. GT8, pp 905-923.

Power, Jay H., and Real, Charles R. 1976. "Shear-Wave Velocity Propagation and Measurement," California Geology, Vol 29, No. 2, pp 27-29.

Redpath, Bruce B. 1973. "Seismic Refraction Exploration for Engineering Site Investigations," Technical Report E-73-4, U. S. Army Engineer Waterways Experiment Station, CE, Vicksburg, Miss.

Richart, F. E., Jr., Hall, J. R., and Woods, R. D. 1970. Vibrations of Soils and Foundations, Prentice-Hall, Englewood Cliffs, N. J.

Viksne, Andy. 1976. "Evaluation of In Situ Shear-Wave Velocity Measurement Techniques," Report No. REC-ERC-76-6, Engineering and Research Center, U. S. Bureau of Reclamation, Denver, Colo.

Woods, Richard D. 1978. "Measurement of Dynamic Soil Properties," Report No. UMEE-78RI, University of Michigan, Ann Arbor. 